\title{
PP2A-activating drugs selectively eradicate TKI-resistant chronic myeloid leukemic stem cells
}

Paolo Neviani, ${ }^{1}$ Jason G. Harb, ${ }^{1}$ Joshua J. Oaks, ${ }^{1}$ Ramasamy Santhanam, ${ }^{1}$ Christopher J. Walker, ${ }^{1}$ Justin J. Ellis, ${ }^{1}$ Gregory Ferenchak, ${ }^{1}$ Adrienne M. Dorrance, ${ }^{2}$ Carolyn A. Paisie, ${ }^{1}$ Anna M. Eiring, ${ }^{1}$ Yihui Ma, ${ }^{2}$ Hsiaoyin C. Mao, ${ }^{2,3}$ Bin Zhang, ${ }^{4}$ Mark Wunderlich, ${ }^{5}$ Philippa C. May, ${ }^{6}$ Chaode Sun, ${ }^{7}$ Sahar A. Saddoughi, 8 Jacek Bielawski, 8 William Blum,2,3 Rebecca B. Klisovic,2,3 Janelle A. Solt, 2,3 John C. Byrd, ${ }^{2,3}$ Stefano Volinia, ${ }^{1,9}$ Jorge Cortes, ${ }^{10}$ Claudia S. Huettner, ${ }^{11}$ Steffen Koschmieder, ${ }^{12}$ Tessa L. Holyoake,13 Steven Devine,2,3 Michael A. Caligiuri,2,3 Carlo M. Croce,1,3 Ramiro Garzon,1,2,3 Besim Ogretmen, ${ }^{8}$ Ralph B. Arlinghaus, ${ }^{14}$ Ching-Shih Chen, ${ }^{2,3}$ Robert Bittman,7 Peter Hokland, ${ }^{15}$ Denis-Claude Roy, ${ }^{16}$ Dragana Milojkovic, ${ }^{6}$ Jane Apperley, ${ }^{6}$ John M. Goldman, ${ }^{6}$ Alistair Reid, ${ }^{6}$ James C. Mulloy, ${ }^{5}$ Ravi Bhatia, ${ }^{4}$ Guido Marcucci, ${ }^{2,3}$ and Danilo Perrotti $1,3,6$

${ }^{1}$ Human Cancer Genetics Program, Department of Molecular Virology Immunology and Medical Genetics, ${ }^{2}$ Department of Internal Medicine, and ${ }^{3}$ Comprehensive Cancer Center, The Ohio State University, Columbus, Ohio, USA. ${ }^{4}$ Department of Hematopoietic Stem Cell and Leukemia Research, City of Hope National Medical Center, Duarte, California, USA. ${ }^{5}$ Experimental Hematology and Cancer Biology, Cincinnati Children's Hospital Medical Center, Cincinnati, Ohio, USA. ${ }^{6}$ Department of Haematology, Hammersmith Hospital, Imperial College London, London, United Kingdom. 7Department of Chemistry and Biochemistry, Queens College of The City University of New York, Flushing, New York, USA

${ }^{8}$ Department of Biochemistry and Molecular Biology, Hollings Cancer Center, Medical University of South Carolina, Charleston, South Carolina, USA. ${ }^{9}$ Department of Morphology and Embryology, Università degli Studi di Ferrara, Ferrara, Italy. ${ }^{10}$ Department of Leukemia, M.D. Anderson Cancer Center, Houston, Texas, USA. ${ }^{11}$ Dana Farber Cancer Institute, Harvard Medical School, Boston, Massachusetts, USA. ${ }^{2}$ Department of Internal Medicine, Hematology and Medical Oncology, University Hospital of Aachen, Aachen, Germany. ${ }^{13}$ Paul O'Gorman Leukaemia Research Centre, Institute of Cancer Sciences, University of Glasgow, Glasgow, United Kingdom. ${ }^{14}$ Department of Molecular Pathology, M.D. Anderson Cancer Center, Houston, Texas, USA. ${ }^{15}$ Department of Hematology, Aarhus University Hospital, Aarhus, Denmark. ${ }^{16}$ Department of Hematology-Oncology, Maisonneuve-Rosemont Hospital and University of Montreal, Montreal, Quebec, Canada.

\begin{abstract}
The success of tyrosine kinase inhibitors (TKIs) in treating chronic myeloid leukemia (CML) depends on the requirement for BCR-ABL1 kinase activity in CML progenitors. However, CML quiescent HSCs are TKI resistant and represent a BCR-ABL1 kinase-independent disease reservoir. Here we have shown that persistence of leukemic HSCs in BM requires inhibition of the tumor suppressor protein phosphatase 2A (PP2A) and expression - but not activity - of the BCR-ABL1 oncogene. Examination of HSCs from CML patients and healthy individuals revealed that PP2A activity was suppressed in CML compared with normal HSCs. TKIresistant CML quiescent HSCs showed increased levels of BCR-ABL1, but very low kinase activity. BCR-ABL1 expression, but not kinase function, was required for recruitment of JAK2, activation of a JAK2/ $\beta$-catenin survival/self-renewal pathway, and inhibition of PP2A. PP2A-activating drugs (PADs) markedly reduced survival and self-renewal of CML quiescent HSCs, but not normal quiescent HSCs, through BCR-ABL1 kinase-independent and PP2A-mediated inhibition of JAK2 and $\beta$-catenin. This led to suppression of human leukemic, but not normal, HSC/progenitor survival in BM xenografts and interference with long-term maintenance of BCR-ABL1-positive HSCs in serial transplantation assays. Targeting the JAK2/PP2A/ $\beta$-catenin network in quiescent HSCs with PADs (e.g., FTY720) has the potential to treat TKI-refractory CML and relieve lifelong patient dependence on TKIs.
\end{abstract}

\section{Introduction}

Chronic myeloid leukemia (CML) is a HSC-derived and progenitor-driven myeloproliferative disorder that may progress from a clinically manageable chronic phase to an incurable blastic phase (1). $B C R-A B L 1$ is a tyrosine kinase whose constitutive activity is essential for CML emergence, maintenance, and progression (1). Most CML patients undergoing tyrosine kinase inhibitor (TKI) monotherapy achieve major or complete molecular response (CMR) with low risk of relapse or progression (2). However, only a few patients in CMR do not relapse after discontinuation of TKI (e.g., imatinib) therapy (3). Persistence of cells from the original

Conflict of interest: The authors have declared that no conflict of interest exists. Citation for this article: J Clin Invest. 2013;123(10):4144-4157. doi:10.1172/JCI68951.
BCR-ABL1 ${ }^{+}$clone in TKI-treated patients, but not in allogeneic transplanted patients in CMR (4), suggests the existence of nonproliferating (quiescent) CML HSCs with innate TKI resistance (5), for which BCR-ABL1 kinase activity appears dispensable (5-8). However, how these cells persist in TKI-responsive patients, and whether BCR-ABL1 expression is required for their survival/ self-renewal, remain unknown. Seemingly, the safety and clinical benefit of various approaches envisioning the direct killing or induction of these leukemic HSCs into cell cycle as a mechanism to restore TKI sensitivity $(9-14)$ is as yet uncertain.

Here we show that BCR-ABL1 expression, but not activity, is important in CML quiescent HSCs because it allows recruitment and activation of JAK 2 that, in turn, enhances $\beta$-catenin activity and induces SET-mediated inactivation of protein phosphatase 

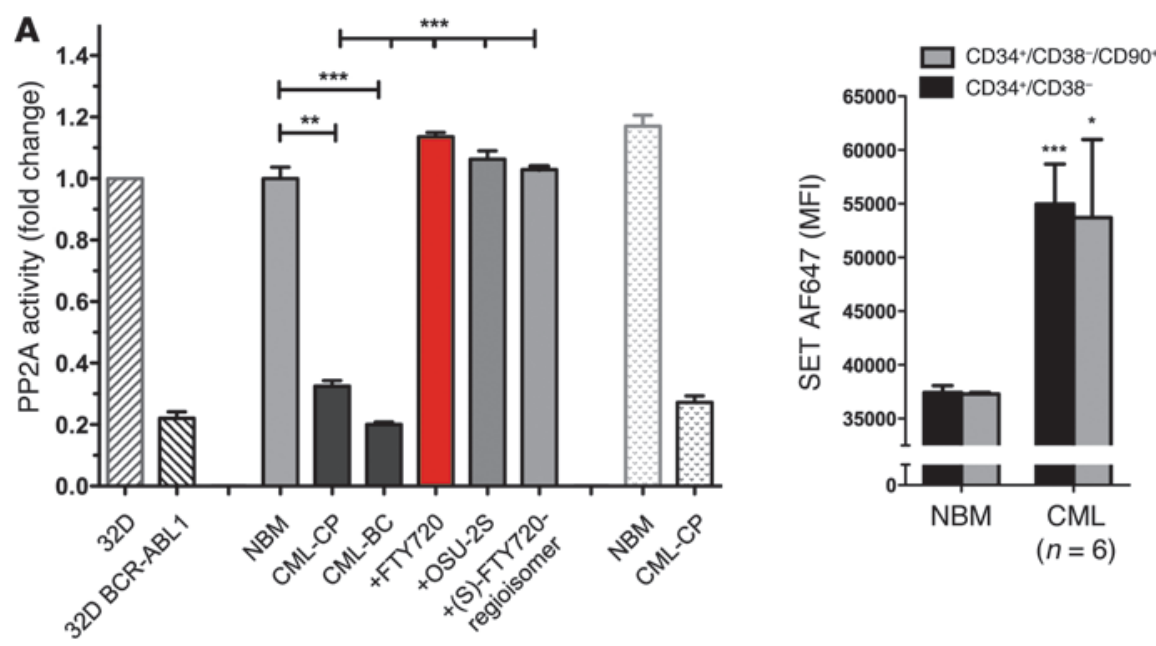

B

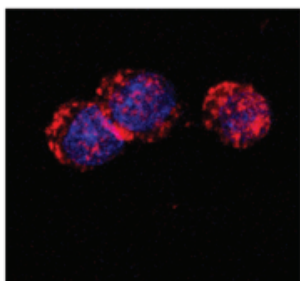

UNT

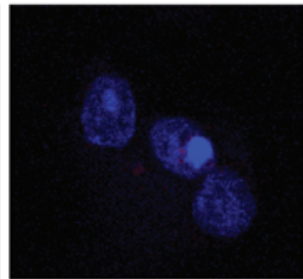

FTY720 $2.5 \mu \mathrm{M}$
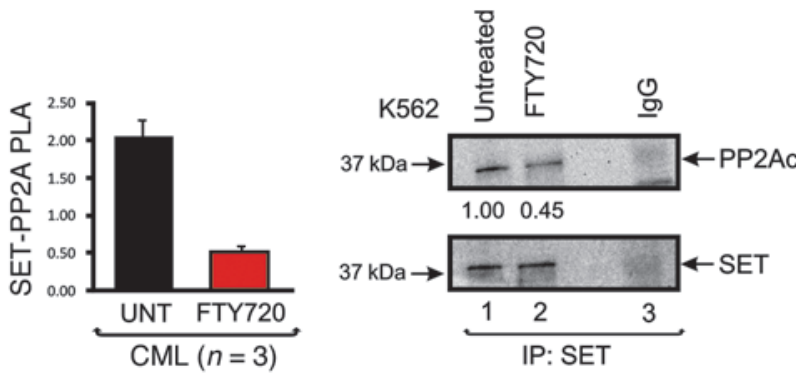

Figure 1

PP2A activity is inhibited in CML HSCs. (A) Left: PP2A phosphatase assay (mean \pm SD) in CD34+CD38- and CD34 $4^{+}$CD $38^{+}$cell fractions from NBM and CML donor BM. 32Dcl3 and 32D-BCR-ABL cells were used as controls. Right: SET levels, measured by intracellular flow staining and expressed as MFI (mean \pm SD), in CD34+CD38- and CD34+CD38-CD90+ NBM and CML BM cells. (B) Left: Confocal microphotographs showing SET-PP2A association (red signals), as well as quantitative proximity ligation assays (PLA; $n=3$ ), on untreated (UNT) and FTY720-treated (24 hours) CD34+CD38- CML cells. Original magnification, $\times 630$. Right: Western blots showing endogenous SET-PP2Ac association in untreated (lane 1) and FTY720-treated (lane 2) K562 cells. Immunoprecipitation with nonrelated IgG (lane 3) was used as control. ${ }^{\star} P<0.05,{ }^{* *} P<0.01,{ }^{* \star *} P<0.001$.

2A (PP2A) (15), a tumor suppressor whose lost activity in cancer, including $\mathrm{CML}$, can be pharmacologically restored (15-18) by PP2A activating drugs (PADs; e.g., 1,9-dideoxy-forskolin, FTY720, OSU-2S, and SET-binding peptides; ref. 19).

FTY720 (fingolimod; Gilenya [Novartis]) is an oral sphingosine analog used in MS patients (20) because it acts as an immunosuppressant that, upon phosphorylation, is internalized by the sphingosine-1-phosphate receptor (S1PR1) (21). FTY720 also has strong anticancer activity that does not require phosphorylation or S1PR1 interaction, but depends on restoration of PP2A function (16-18). FTY720-induced PP2A activity promotes BCRABL1 inactivation/degradation and inhibition of survival factors (e.g., JAK2, Akt, and ERK1/2) $(15,16)$. This results in apoptosis of $\mathrm{CD}_{3} 4^{+}$progenitors from TKI-sensitive and -resistant CML patients, but not from healthy individuals, which already harbor highly active PP2A $(15,16)$, and ultimately translates into longterm survival with normal myelopoiesis and absence of toxicity in BCR-ABL1+ leukemic mice (16).

Herein, we provide evidence that restoration of PP2A activity by FTY720 or its nonimmunosuppressive derivatives (S)-FTY720OMe, (S)-FTY720-regioisomer, and OSU-2S selectively suppressed survival of CML, but not normal quiescent HSCs, both in vitro and in vivo. Mechanistically, FTY720 disrupted the SET-PP2A interaction, thereby allowing $\mathrm{PP} 2 \mathrm{~A}$ reactivation, which inhibited BCR-ABL1-recruited JAK2 and impaired $\beta$-catenin-dependent survival through GSK-3 $\beta$ activation. These findings may further CML therapy into a setting where patients are brought into CMR by TKIs and possibly cured by FTY720 or its derivatives.

\section{Results}

Survival and self-renewal of quiescent CML HSCs requires silencing of the PP2A tumor suppressor and is modulated by FTY720 and its nonimmunosuppressive derivatives. In the stem cell-enriched $\mathrm{CD} 34^{+} \mathrm{CD} 38^{-}$cell fraction (Supplemental Figure 1A; supplemental material available online with this article; doi:10.1172/JCI68951DS1), levels of PP2A phosphatase activity were $\sim 77 \%$ and $\sim 84 \%$ lower in CML chronic phase (CML-CP, $n=3$ ) and blast crisis (CML-BC; $n=3$ ), respectively, than in HSCs derived from normal BM (NBM) of healthy individuals $(n=4)$ (Figure $1 \mathrm{~A}$, left). Furthermore, treatment of leukemic HSCs $(22,23)$ with FTY720 - at a nontoxic concentration for normal CD34 ${ }^{+}$progenitors (16) - restored PP2A activity at levels superimposable to those observed in the identical cell fraction from healthy donors. As expected, PP2A activity was inhibited in CD $34^{+} \mathrm{CD} 38^{+} \mathrm{CML}-\mathrm{CP}$ cells compared with normal progenitors and in BCR-ABL1- versus vector-expressing myeloid 32Dcl3 precursors. Accordingly, levels of the endogenous PP2A inhibitor SET 
A

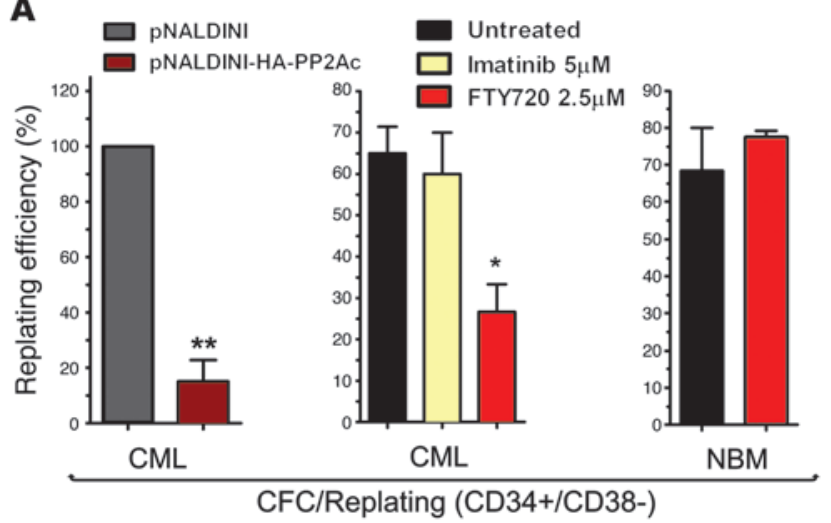

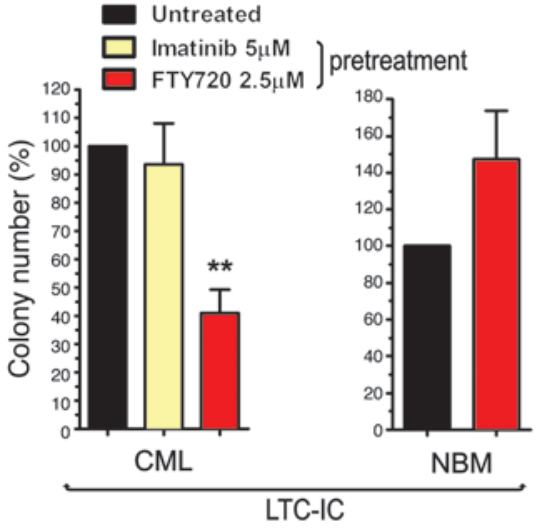

B

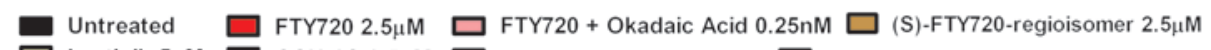

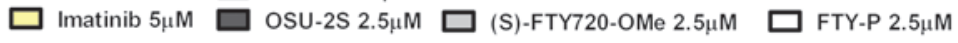
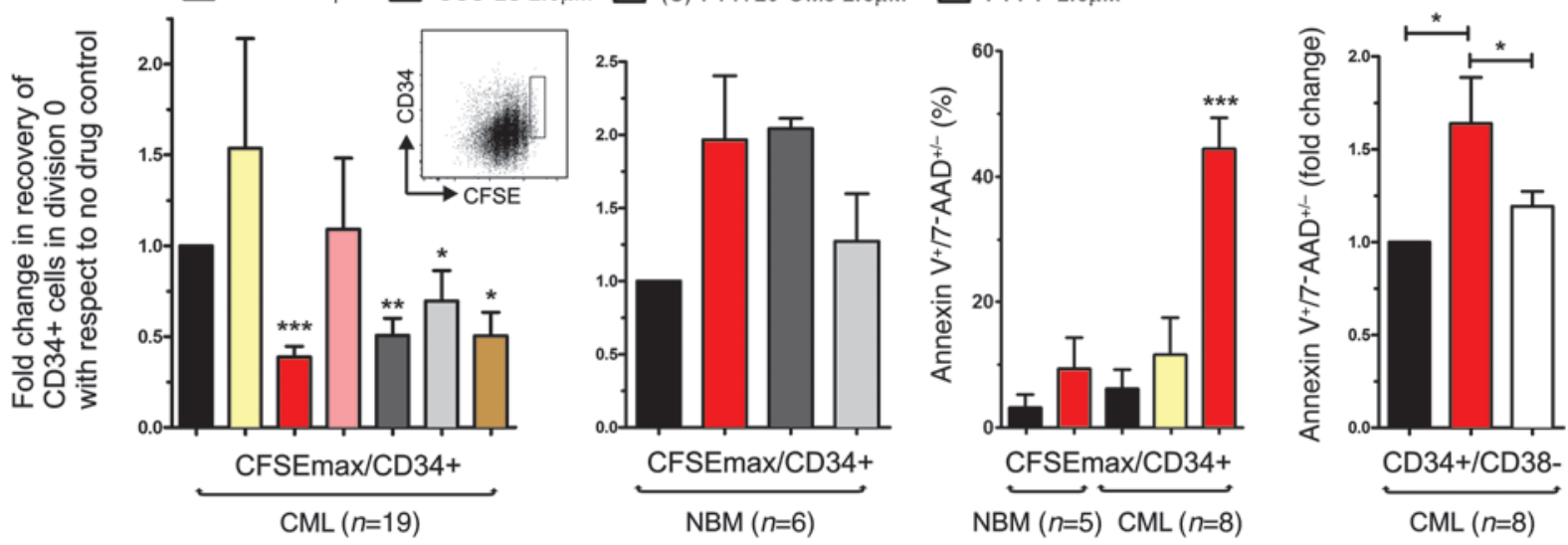

C

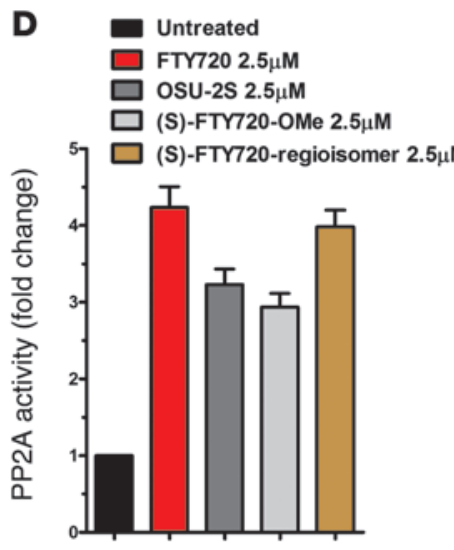

莺 蒡

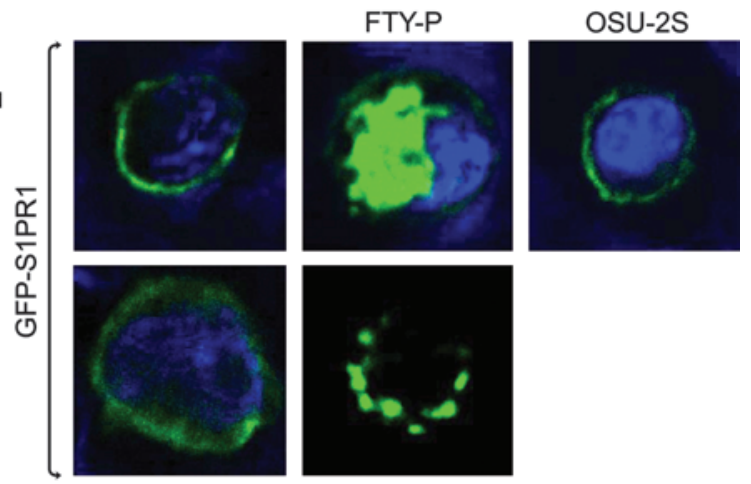

32D-BCR/ABL

(S)-FTY720-OMe (S)-FTY720-regioisomer

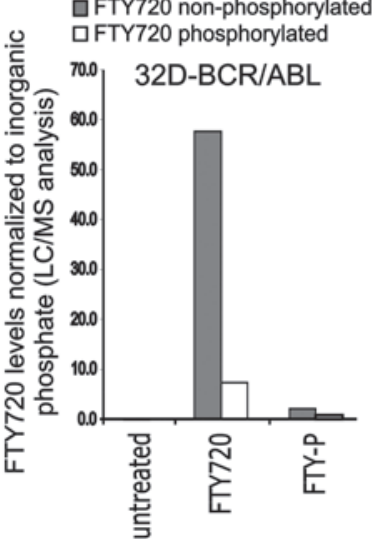

$\mathbf{E}$ $\begin{array}{cccc}\text { FTY720 OSU-2S } & \begin{array}{c}\text { (S)-FTY720- } \\ \text { OMe }\end{array} & \begin{array}{l}\text { (S)-FTY720 } \\ \text { regioisomer }\end{array}\end{array}$

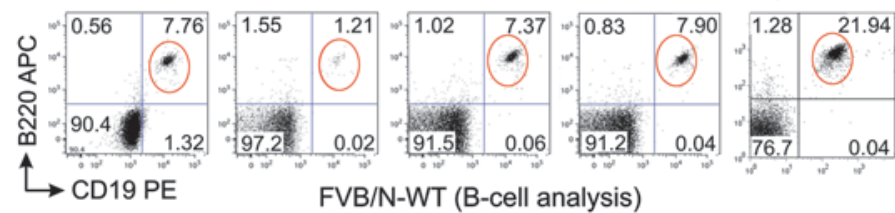

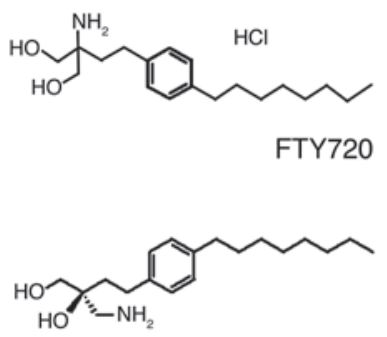

(S)-FTY720-regioisomer

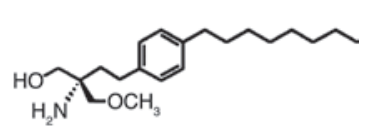

(S)-FTY720-OMe

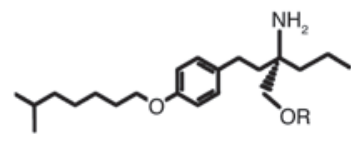

OSU-2S 


\section{Figure 2}

FTY720 and its nonimmunosuppressive derivatives decrease survival and self-renewal of quiescent CML HSCs. (A) CFC/replating results showing replating efficiency of single CFC colonies from $\mathrm{CD} 34^{+} \mathrm{CD} 38^{-}$ CML and NBM cells ectopically expressing HA-tagged PP2Ac or treated with FTY720 or imatinib. LTC-IC results show number of colonies derived from clonogenic assays of CML and NBM cells cultured for 6 weeks and exposed to the indicated drug during the first week of culture. (B) Number of quiescent CFSE ${ }^{\max } \mathrm{CD} 34^{+}$cells (gated cells; inset) in untreated and drug-treated CFSE-labeled CD34+ NBM and CML BM cells. Annexin-V/7-AAD staining shows percent CFSEmax CD34+ or CD34+CD38- CML and NBM cells undergoing apoptosis. (C) Intracellular levels of nonphosphorylated and phosphorylated FTY720 in 32D-BCR-ABL cells treated with FTY720 $(2.5 \mu \mathrm{M})$ or FTY-P $(2.5 \mu \mathrm{M})$, as measured by LC/ESI/MS/MS. (D) Left: PP2A phosphatase activity assay (mean $\pm \mathrm{SD}$ ) performed on 32D-BCR-ABL cells treated with FTY720 or with its nonimmunosuppressive derivatives (S)-FTY720-OMe, (S)-FTY720-regioisomer, and OSU-2C. Right: Confocal microphotographs demonstrating lack of phosphorylation of the FTY720 derivatives by showing the distribution of GFP-tagged S1PR1 after treatment with FTY-P (positive control), (S)-FTY720-OMe, (S)-FTY720-regioisomer, and OSU-2S. Original magnification, $\times 630$. (E) Percent CD19+B220 ${ }^{+}$B cells in the PB of FVB/N WT mice after i.p. injection with FTY720, (S)-FTY720-OMe, (S)-FTY720-regioisomer, or OSU-2S. Molecular structures of FTY720, (S)-FTY720-OMe (48), (S)FTY720-regioisomer (48), and OSU-2S (49) are also shown. ${ }^{*} P<0.05$, ${ }^{\star \star} P<0.01,{ }^{* \star *} P<0.001$, Student's $t$ test.

(also known as I2PP2A) were significantly higher in CML than $\mathrm{NBM} \mathrm{CD} 34^{+} \mathrm{CD} 38^{-}$and $\mathrm{CD} 34^{+} \mathrm{CD} 38^{-} \mathrm{CD} 90^{+}$(Figure $1 \mathrm{~A}$, right) HSC-enriched cell fractions (Supplemental Figure 1A), and its association with the catalytic subunit of PP2A (PP2Ac) was efficiently disrupted by FTY720 in both HSC-enriched CD34 ${ }^{+}$CD $38^{-}$ CML $(n=3)$ and Philadelphia chromosome-positive $\left(\mathrm{Ph}^{+}\right) \mathrm{K} 562$ cells (Figure 1B). Similarly, PP2A activity was inhibited by $80 \%$ in lineage-negative ( $\left.\mathrm{Lin}^{-}\right) \mathrm{BM}$ cells from leukemic BCR-ABL1-tg mice $(n=8)$ (Supplemental Figure 1B and ref. 24).

The relevance of PP2A silencing in CML HSC self-renewal and growth/survival was assessed by $\mathrm{CFC} /$ replating and long-term culture-initiating cell (LTC-IC) assays, respectively. A significant reduction of approximately $60 \%-90 \%$ in replating efficiency was observed upon HA-tagged PP2Ac lentiviral transduction $(P<0.01)$ $(n=3)$ or FTY720 treatment $(P<0.01)$ of human CD34 ${ }^{+} \mathrm{CD} 38^{-}$ CML $(n=3)$ and mouse $\operatorname{Lin}^{-}(n=3)$ and Lin $^{-} \mathrm{Sca}-1^{+} \mathrm{c}-\mathrm{Kit}^{+}(\mathrm{LSK})$ $(n=3)$ BCR-ABL1-tg cells (Figure 2A and Supplemental Figure 1B). Conversely, FTY720 did not affect the replating ability of $\mathrm{CD}^{2} 4^{+} \mathrm{CD} 38^{-}$cells derived from $\mathrm{NBM}(n=3)$ (Figure $\left.2 \mathrm{~A}\right)$. Similarly, LTC-ICs were inhibited by $60 \%-70 \%(P<0.01)$ in FTY720treated $(n=9)$ versus untreated CML cells, but it did not reduce the number of LTC-ICs derived from healthy donors $(n=3)$ (Figure $2 \mathrm{~A})$. As expected (7), imatinib did not alter CFC/replating and LTC-IC efficiency of leukemic HSCs $(n=9)$ (Figure 2A and Supplemental Figure 1B).

Impaired self-renewal/survival of FTY720-treated leukemic HSCs was accompanied by a pronounced decrease in the absolute number of CFSE ${ }^{\max } \mathrm{CD} 34^{+}$quiescent leukemic HSCs (Figure 2B, inset); in fact, PP2A reactivation by FTY720 triggered apoptosis $\left(\right.$ Annexin $\left.\mathrm{V}^{+}\right)$and induced a $\sim 60 \%$ decrease in CML HSCs $(n=19$; $P<0.001)$ and a $\sim 90 \%$ decrease in BCR-ABL1-tg CFSE ${ }^{\max }$ HSCs (Figure 2B and Supplemental Figure 1B). This effect was PP2A mediated, as it was antagonized by $0.25 \mathrm{nM}$ okadaic acid (Figure 2B), which reportedly specifically inhibits PP2A activity only
$(15,16)$. Consistent with the lack of FTY720 activity and with the already high levels of PP2A in $\mathrm{CD}_{3} 4^{+}$progenitors $(15,16)$ and $\mathrm{CD} 34^{+} \mathrm{CD} 38^{-}$HSC-enriched BM cell fractions from healthy individuals $(n=6)$ (Figure 1A and Supplemental Figure 1C), FTY720 neither induced apoptosis nor reduced the absolute number of $\mathrm{CFSE}^{\max } \mathrm{CD} 34^{+}$quiescent HSCs from NBM samples (Figure 2B). Interestingly, a nonsignificant increase $(P=0.07)$ in the $\mathrm{CFSE}^{\text {max }}$ fraction was observed upon treatment of $\mathrm{CD} 34^{+} \mathrm{NBM}$ cells with FTY720 and its derivatives (Figure 2B), in agreement with the reported ability of FTY720 to promote growth and BM homing of normal CD34 ${ }^{+} \mathrm{CD} 38^{-}$HSCs (25).

Although more than 90\% of intracellular FTY720 remained unphosphorylated in BCR-ABL1+ cells (Figure 2C), FTY720 induces lymphopenia upon phosphorylation and S1PR1-mediated internalization (26). Thus, we tested the activity of 3 FTY720 derivatives, (S)-FTY720-OMe, (S)-FTY720-regioisomer, and OSU$2 S$, which activated PP2A both in CML HSCs and in progenitors (Figure 1A and Figure 2D) without triggering S1PR1 internalization or inducing B-lymphopenia (Figure 2, D and E). These drugs significantly reduced the number of CML, but not normal, $\mathrm{CFSE}^{\max } \mathrm{CD} 4^{+}$quiescent cells (Figure 2B). Conversely, the immunosuppressor and phosphorylated FTY720 (FTY-P) neither activated PP2A (17) nor reduced numbers or induced apoptosis of CD34 ${ }^{+} \mathrm{CD} 38^{-} \mathrm{CML}$ cells $(n=8 ; P<0.05)$ (Figure $\left.2 \mathrm{~B}\right)$.

$P A D$-induced apoptosis of quiescent $H S C$ s requires $B C R-A B L 1$ expression, but not its activity. FTY720 induces PP2A-dependent BCRABL1 dephosphorylation $(15,16)$, and we found it to increase imatinib-induced apoptosis of $\mathrm{CD} 34^{+} \mathrm{CML}$ progenitors (Figure $3 \mathrm{~A}$, left). However, a FTY720-induced decrease in the levels of Y245-phosphorylated BCR-ABL1 ( ABL $^{\mathrm{Y} 245}$ ) was observed in the bulk of CD $34^{+}$cells, but not in the CFSE ${ }^{\max }$ fraction (Figure 3B), which indicates that inhibition of BCR-ABL1 activity by FTY720 did not occur in the quiescent fraction of CD $34^{+}$CML cells. In the latter, FTY720-induced apoptosis was not influenced by BCRABL1 kinase inhibition (Figure 3A, right). In fact, suppression of BCR-ABL1 activity (Figure 3B) did not result in apoptosis of quiescent CML HSCs (Figure 2B and Figure 3A). Interestingly, $\sim 7$-fold lower BCR-ABL1 activity was found in $\mathrm{CFSE}^{\max } \mathrm{CD} 34^{+}$versus total CD34+ CML cells $(P<0.05)$ (Figure $3 \mathrm{~B})$. Analysis of BCR-ABL1 levels and phosphorylation in quiescent and dividing CML HSCs $(n=3)$ showed higher expression in quiescent cells that did not depend on increased BCR-ABL1 transcription (Figure 3C). Conversely, levels of phosphorylated (active) BCR-ABL1 in quiescent HSCs were reduced or identical to those in dividing cells (Figure 3C), suggesting a role for BCR-ABL1 in CML HSCs independent of its kinase activity. Indeed, ectopic expression of a kinase-deficient K1172R BCR-ABL1 mutant efficiently suppressed PP2A activity in $32 \mathrm{Dcl} 3$ myeloid cells and in primary mouse LSK cells (Figure 4A and Supplemental Figure 2), thereby indicating that BCR-ABL1 expression and not its activity is critical for CML HSC survival.

JAK2 activation is essential for CML HSC survival and requires both expression of BCR-ABL1 and suppression of PP $2 A$ activity. In BCR-ABL1 ${ }^{+}$ myeloid progenitors, JAK2 interacts with BCR-ABL1 and upregulates SET leading to PP2A inactivation (27), while forced PP2A reactivation results in JAK2 inhibition (15). Because BCR-ABL1 activity in $\mathrm{CD} 4^{+} \mathrm{CD} 38^{-}$cells is reduced by JAK2 inhibition, and JAK2 inhibited PP2A and was associated with and equally induced by WT and kinase-deficient K1172R BCR-ABL1 in primary mouse LSK and 32Dcl3 myeloid cells (Figure 4, A and B, and Supplemental Figure 2), it is possible that BCR-ABL1 recruits JAK2 and allows its activation 
A

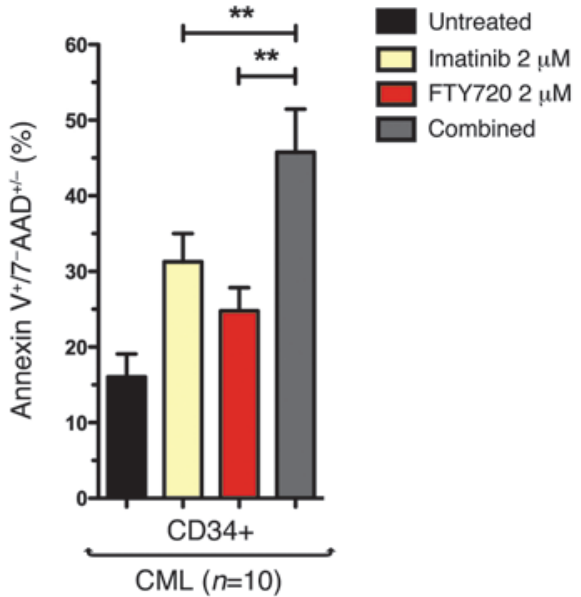

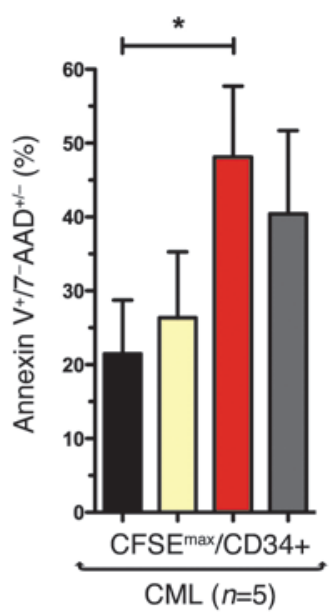

\section{Figure 3}

BCR-ABL1 activity, but not its expression, is low in CML quiescent stem cells. (A) Annexin-V/7-AAD staining shows percent apoptotic CD34+ $\mathrm{CML}$ progenitors and CFSE ${ }^{\max C D 34+}$ TKI-resistant quiescent CML cells upon exposure to FTY720 and imatinib, alone or in combination. (B) Active BCR-ABL1 ( $p A B L^{\mathrm{Y} 245}$ ) levels in $\mathrm{CFSE}^{\max } \mathrm{CD} 34^{+}$and $\mathrm{CD} 34^{+}$cells from untreated and FTY720- or imatinib-treated CML samples. A representative flow cytometry histogram overlay is also shown. (C) Left: Gating strategy to isolate quiescent CFSEmax CD34+ cells versus dividing CD34+ cells and their CD34-CD38 flow profile. Middle and right: BCR-ABL1 activity $(\alpha-p Y)$ and protein $(\alpha-A b l)$. mRNA levels (relative to K562 cells) in FACS-sorted quiescent (CFSEmax) cells were compared with dividing (Div1 and Div2) CD34+ CML cells. Actin levels were detected as a control. ${ }^{*} P<0.05,{ }^{*} P<0.01$, Student's $t$ test.
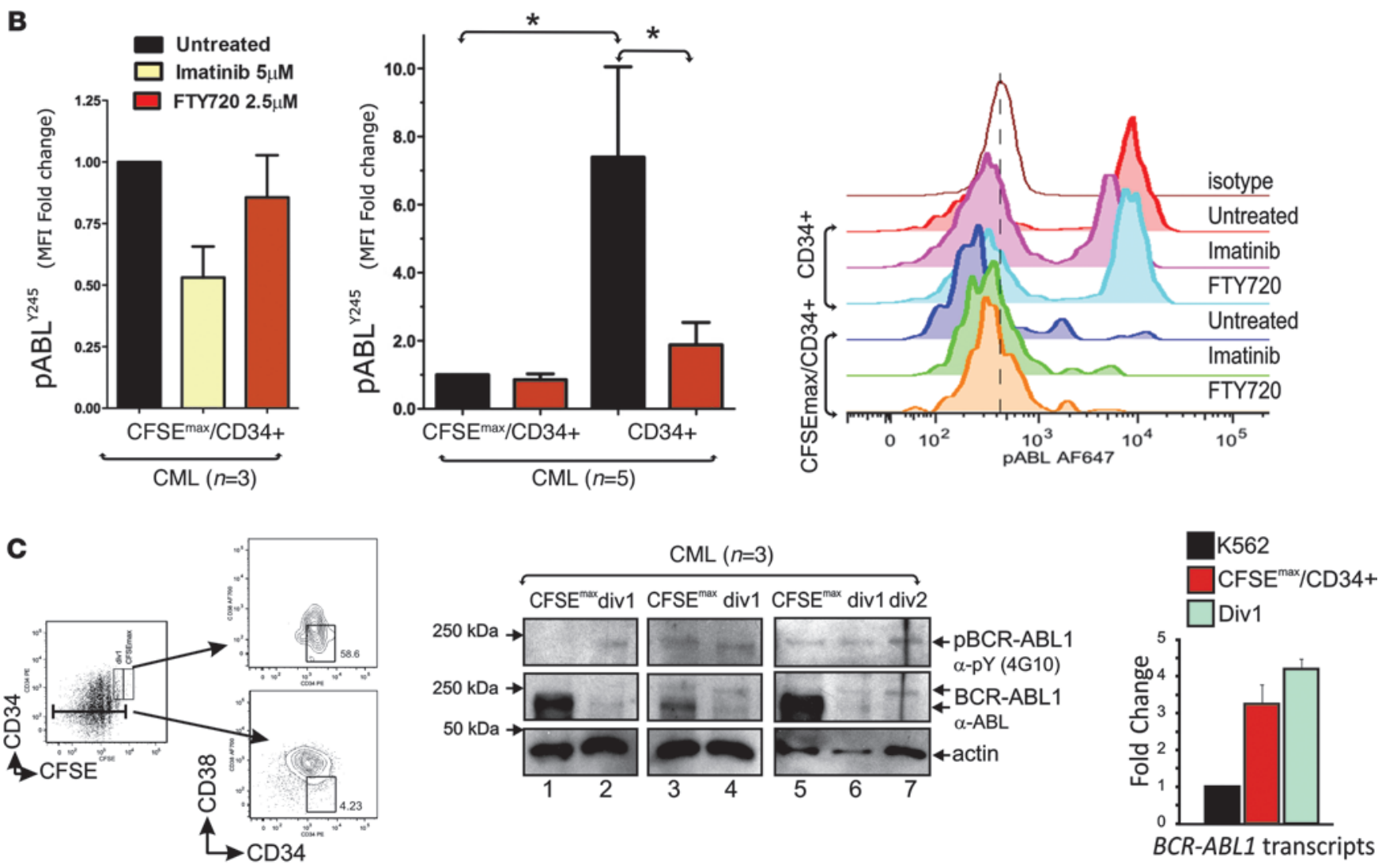

in a BCR-ABL1 kinase-independent manner. This, in turn, might lead to JAK2-dependent BCR-ABL1 stabilization (28) and regulation of HSC survival. Indeed, JAK2 activity was strongly enhanced in $\mathrm{CML}(n=3)$ compared with $\mathrm{NBM}(n=3) \mathrm{CFSE}^{\max } \mathrm{CD} 34^{+}$cells and reduced in HSC-enriched $\mathrm{CD} 34^{+} \mathrm{CD} 38^{-} \mathrm{CML}$ cells upon shRNAmediated BCR-ABL1 downregulation $(n=3)$ or FTY720 treatment $(n=4)$ (Figure 4B). Furthermore, pharmacologic JAK2 inhibition by TG101348, TG101210, and/or JAK inhibitor 1 decreased CML LTC-IC $(n=4)$ and CFC/replating $(n=3)$ activities by $80 \%$ and $72 \%$, respectively, and decreased by $51 \%$ the number of quiescent CML $(n=8)$, but not NBM $(n=5)$, HSCs in an okadaic acid-sensitive manner $(n=3)$ (Figure 4C), which indicates that the effect of JAK2 inhibition on CML HSC survival/self-renewal is mediated by PP2A.
PP2A and JAK2 control the activity of the Wnt signaling factor $\beta$-catenin in a BCR-ABL1 kinase-independent and PAD-sensitive manner. Because of the reported interplay of PP2A with JAK2 (27) and $\beta$-catenin (29), and given the essential role played by $\beta$-catenin in the regulation of survival/self-renewal of normal and leukemic stem cells $(14,30-32)$, we hypothesized that $\beta$-catenin may represent the downstream effector of the BCR-ABL1/JAK2 axis in CML HSCs. Indeed, shRNA-mediated JAK2 downregulation in $\mathrm{CD} 34^{+} \mathrm{CD} 38^{-}$ CML cells significantly decreased the expression of $\beta$-catenin (Figure $5 \mathrm{~A}$ ). Moreover, $\beta$-catenin expression was markedly decreased in CD $34^{+} \mathrm{CD} 38^{-}$CML cells transduced with PP2Ac or in leukemic HSCs exposed to FTY720 (PP2A activation), but not in those treated with imatinib (BCR-ABL1 inhibition) (Figure 5B and Supple- 
A

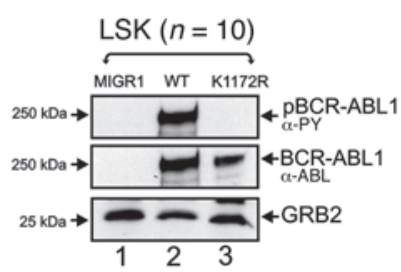

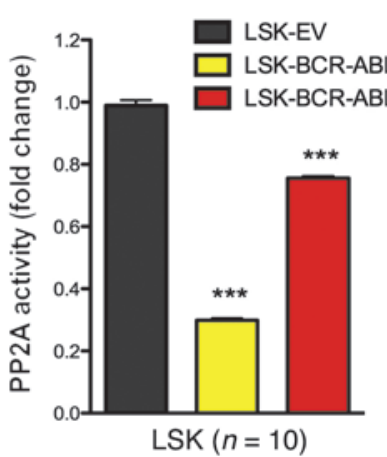

$\operatorname{LSK}(n=10)$

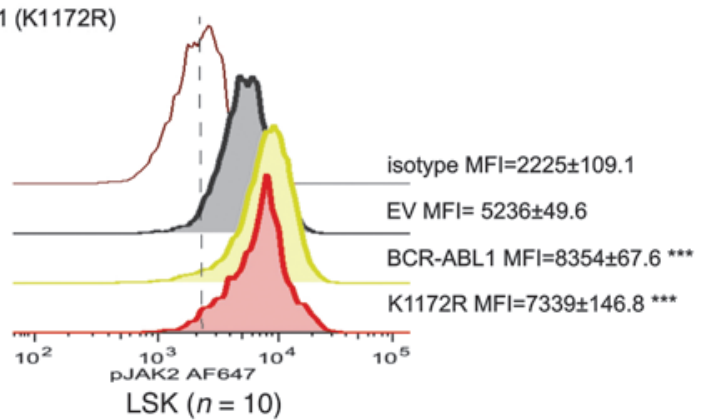

B
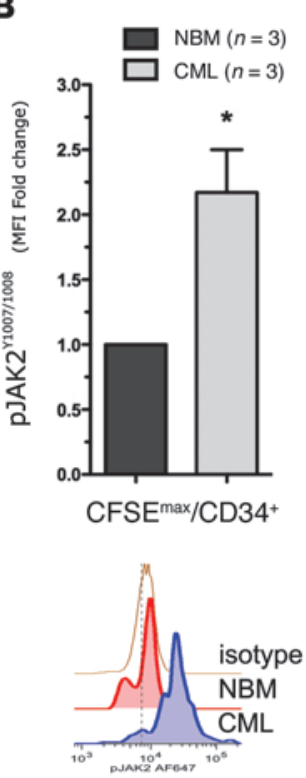
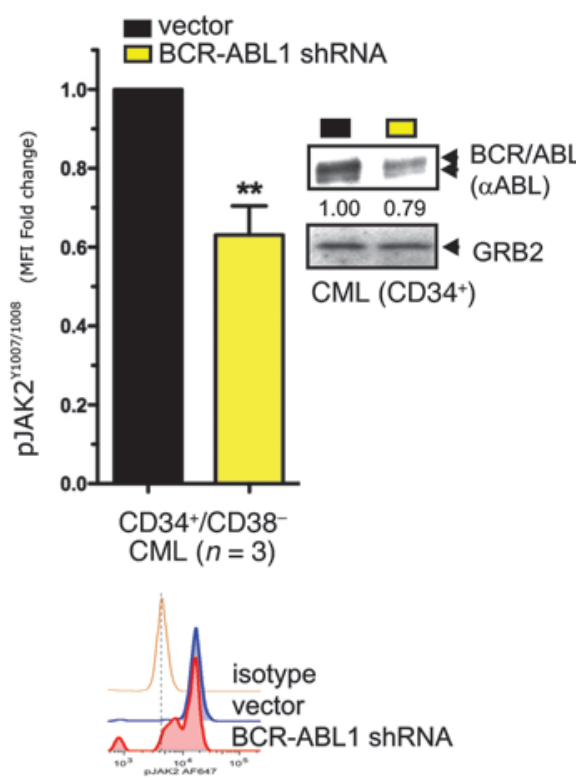
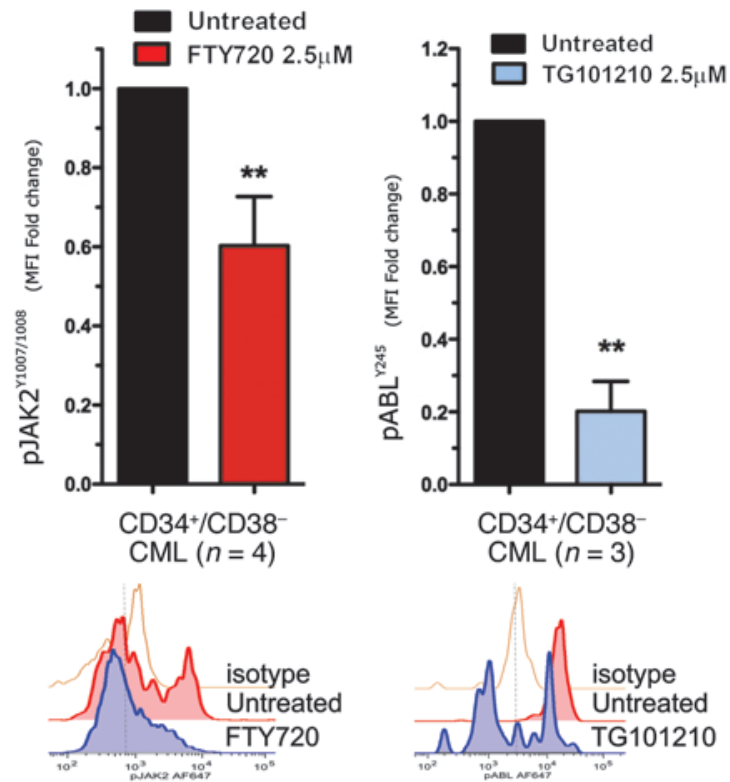

C

Untreated

Jak inhibitor $11 \mu \mathrm{M}$

TG101348 $1 \mu \mathrm{M}$

TG101348 $0.1 \mu \mathrm{M}$

TG101348 $1 \mu \mathrm{M}+$ Okadaic Acid $0.25 \mathrm{nM}$
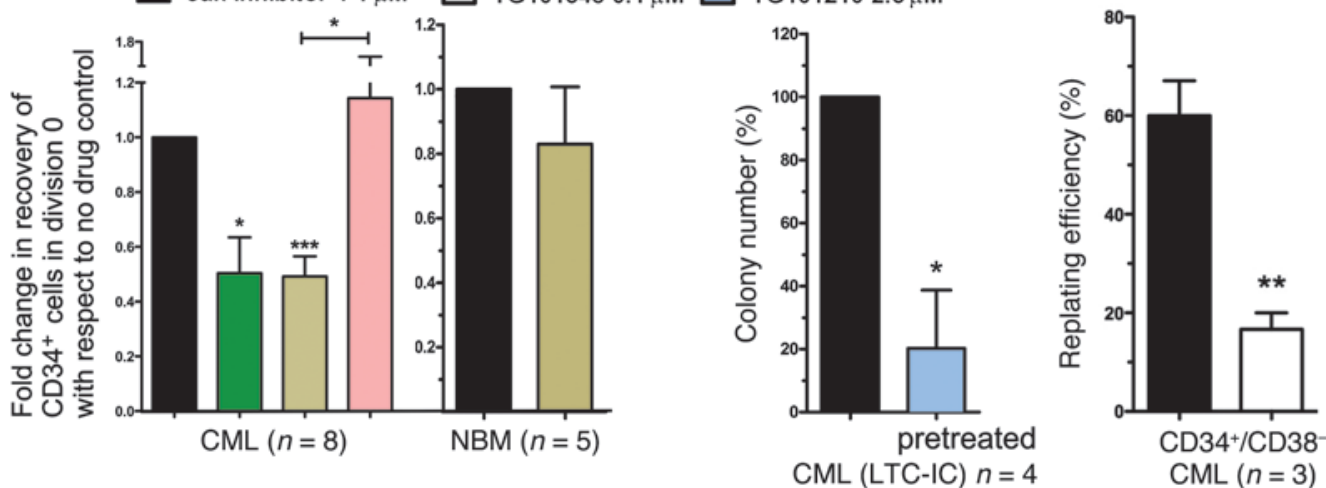

Figure 4

JAK2 activity requires BCR-ABL1 expression and is essential for CML HSCs survival. (A) Left: BCR-ABL1 and JAK2 protein activity and expression in MIGR1-empty vector, WT BCR-ABL1-expressing, and K1172R BCR-ABL1-expressing LSK cells $(n=10)$. GRB2 levels were detected as loading control. Middle: PP2A phosphatase activity assay (mean \pm SD) of MIGR1-empty vector (EV), WT BCR-ABL1-expressing, and K1172R BCR-ABL1-expressing LSK cells. Right: Flow cytometric analysis of active JAK2 (pJAK2) levels in MIGR1-empty vector, BCR-ABL1-, and

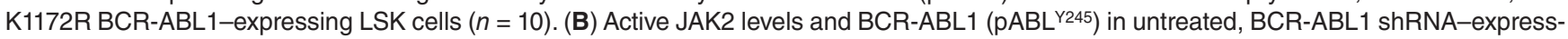
ing, and FTY720-treated CFSE ${ }^{\max C D} 34^{+}$and CD34+CD38- cells from NBM and/or CML samples. Representative flow cytometry histogram overlays are shown. Inset: BCR-ABL1 levels in CML CD34+ cells transduced with a shRNA specific for the b3a2 BCR-ABL1 junction. Levels of BCR-ABL1 expression normalized to that of GRB2 are expressed as arbitrary densitometric units. (C) Effect of JAK2 inhibitors on (left) CFSEmax/ CD34+ frequency, (middle) LTC-IC (6 weeks), and (right) replating efficiency of CML cells. ${ }^{\star} P<0.05,{ }^{\star \star} P<0.01$, ${ }^{\star \star \star} P<0.001$, Student's $t$ test. 
A

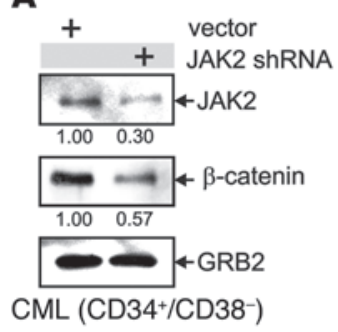

B

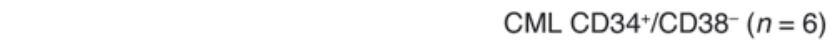

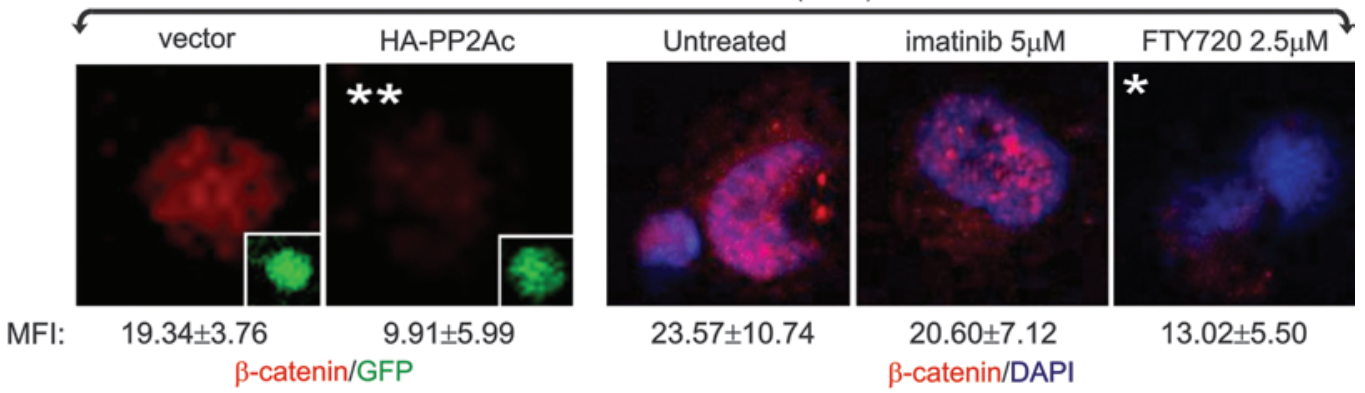

C

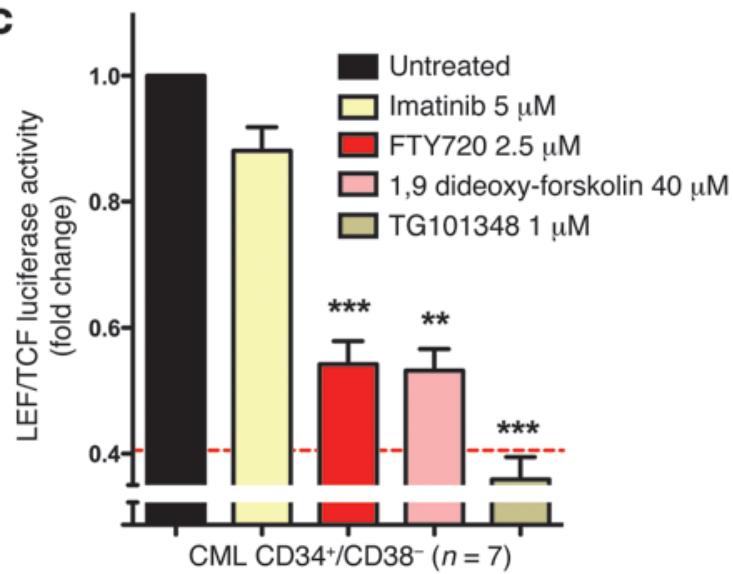

D

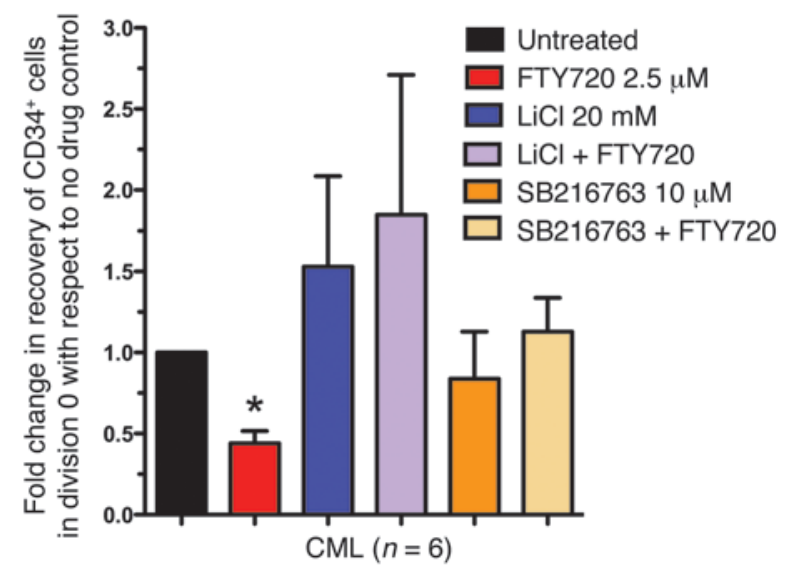

Figure 5

$\beta$-catenin activity is controlled by PP2A and JAK2 in a BCR-ABL1 kinase-independent manner. (A) Western blot showing the effect of JAK2 downregulation by shRNA on $\beta$-catenin expression in CML CD34+CD38- cells. GRB2 was detected as a control and used to normalize levels of JAK2 and $\beta$-catenin (expressed as arbitrary densitometric units). (B) Confocal microphotographs, representative of 3 independent experiments, showing expression levels of $\beta$-catenin (MFI \pm SD) in CML CD34 ${ }^{+}$CD38- cells lentivirally transduced with HA-tagged PP2Ac or treated with FTY720 or imatinib. Original magnification, $\times 630$. (C) Luciferase assays show $\beta$-catenin-driven (LEF/TCF) transcriptional activity in CD34+CD38- CML cells untreated or treated with the indicated drugs. Red dashed line shows the baseline luciferase levels in cells transduced with the negative control pfuBAR. (D) Effect of GSK-3 $\beta$ inhibitors on FTY720-induced reduction of quiescent CFSEmax CD34+ cells. ${ }^{*} P<0.05,{ }^{* \star} P<0.01,{ }^{* \star \star} P<0.001$.

mental Figure 3), consistent with the notion that PP2A is capable of suppressing $\beta$-catenin activity/expression (29). The importance of PP2A for $\beta$-catenin function, and its dependence on JAK2 (but not BCR-ABL1) activity, was confirmed by LEF/TCF luciferase assays. In fact, the PP2A activators FTY720 and 1,9-dideoxy-forskolin and the JAK2 inhibitor TG101348, but not imatinib, markedly impaired $\beta$-catenin transcriptional activity in CML HSCs and BCR-ABL1 ${ }^{+}$myeloid cells (Figure 5C and Supplemental Figure $3 \mathrm{C})$. As $\beta$-catenin inactivation depends on phosphorylation by GSK-3 $\beta$, which undergoes activation by PP2A, treatment of CD $34^{+}$ CML cells with the GSK-3 $\beta$ inhibitors $\mathrm{LiCl}$ and SB216763 induced accumulation of $\mathrm{CFSE}^{\max } \mathrm{CD} 34^{+}$quiescent cells, even in the presence of FTY720 (Figure 5D). Thus, $\beta$-catenin inhibition by PP2Aactivated GSK-3 $\beta$ is essential for the detrimental effect of FTY720 on quiescent CML HSC survival/self-renewal.

FTY720 suppresses leukemic HSC survival in vivo. To assess the biological importance and therapeutic relevance of $\mathrm{PP} 2 \mathrm{~A}$ reactivation on CML HSC survival, we used 2 different approaches. In the first set of experiments, PP2A reactivation by FTY720 (4-week treatment) reduced leukemic LSK cells by $\geq 50 \%$ and splenic and/ or BM long-term HSCs (LT-HSCs) by $\geq 70 \%$ in congenic recipients transplanted with total BM $(n=16)$ or LSK $(n=13)$ cells from BCR-ABL1-tg mice (Figure 6, A and B, and ref. 13). In this first set of experiments, leukemic engraftment was observed in $25 \%$ and $83 \%$ of secondary recipients that received BM from FTY720- and vehicle-treated mice, respectively (Table 1 , experiment 1 ). Limiting dilution assays showed that FTY720 reduced leukemic LTHSC frequency by $\sim 80 \%$ (untreated donor, $2.23 \times 10^{-6}$ LT-HSCs; FTY720-treated donor, $0.45 \times 10^{-6}$ LT-HSCs), as determined by Poisson distribution and the method of maximum likelihood (Table 1, experiment 2).

Accordingly, in experiments with xenotransplanted CML patient cells, $\sim 83 \%, \sim 85 \%$, and $\sim 97 \%$ reductions in total human CD45-expressing $\left(\mathrm{hCD}_{4} 5^{+}\right)$cells, $\mathrm{CD} 45^{+} \mathrm{CD} 34^{+}$progenitors, and CD $45^{+} \mathrm{CD} 34^{+} \mathrm{CD} 38^{-}$HSCs $(P<0.001)$, respectively, were evident after 4 and 8 weeks of FTY720 treatment ( 8 and 16 weeks after transplant) in BM of mice (8-10 per group) engrafted with CML$\mathrm{BC}(n=3) \mathrm{CD}^{2} 4^{+} \mathrm{BM}$ cells (Figure $6, \mathrm{C}$ and $\left.\mathrm{D}\right)$. Likewise, $\mathrm{CML}$ hCD $45^{+} \mathrm{CD} 33^{+}$myeloid cells were also reduced (Supplemental Figure 4). Notably, similar numbers of hCD $45^{+}$cell were found in untreated CML mice at 8 and 16 weeks after transplant (Figure $6 \mathrm{D}$ ). This, together with the significant decrease in $B C R-A B L 1$ transcripts and the presence of mostly normal hCD $45^{+}$cells in BM of FTY720-treated animals transplanted with a CML-BC sample containing a $25 \%$ BCR-ABL1- metaphases (Figure $6 \mathrm{~F}$ ), is indicative of an expansion of human normal hematopoietic cells 
that, as expected, do not represent a target of FTY720. Accordingly, FTY720 did not exert noteworthy effects on identical human cell fractions from mice engrafted with umbilical cord blood (UCB) $(n=3) \mathrm{CD}^{+} 4^{+}$cells; however, as expected, it reduced numbers of circulating $\mathrm{B}\left(\mathrm{CD} 19^{+}\right)$and $\mathrm{T}\left(\mathrm{CD}^{+}\right)$cells (Figure $6 \mathrm{E}$ and Supplemental Figure 4). Thus, pharmacologic reactivation of PP2A by FTY720 markedly and selectively reduces the number of leukemic HSCs and progenitors responsible for CML emergence, maintenance, and relapse, both in vitro and in vivo.

\section{Discussion}

The notion that TKIs do not kill quiescent CML HSCs (5) because BCR-ABL1 activity is dispensable for their survival $(7,8)$ suggests that other aberrantly regulated signals control leukemic stem cell persistence (5, 33-35). Our present findings support the hypothesis that BCR-ABL1 expression per se is required for survival of CML HSCs. BCR-ABL1 expression, but not its kinase activity, was indeed substantially higher in human quiescent than in dividing HSCs; this upregulation was not transcriptional, but likely relies on stabilization (28) of BCR-ABL1 protein in a nearly inactive state. A similar pattern of BCR-ABL1 expression was also observed in leukemic HSCs and progenitors from BCR-ABL1-tg mice (24). Moreover, BCR-ABL1 downregulation and expression of a kinase-deficient BCR-ABL1 mutant in quiescent HSCs allowed JAK2 activation that, in turn, controlled quiescent CML HSC survival/self-renewal, likely upon stabilizing BCR-ABL1 (Figure 4E). Accordingly, JAK2 activity was higher in CML HSCs than in normal quiescent HSCs, JAK2 inhibition reduced survival/self-renewal of CML HSCs, and a previous report showed that levels of BCR-ABL1 and its JAK2dependent Y177 phosphorylation decrease upon JAK2 downregulation in $\mathrm{CD}_{3} 4^{+}$progenitors (28). These findings indicate that JAK2 stabilizes BCR-ABL1 and uses it as a scaffold to control survival signals. Indeed, BCR-ABL1 and JAK2 coexist in a complex containing HSP90 and other signaling proteins (e.g., Akt, Lyn, GSK-3 $\beta$, Erk, and STAT3) in K562 cells (36). Importantly, short-term imatinib treatment did not destroy this complex, but a dual BCR-ABL1/ JAK2 kinase inhibitor rapidly disassembled this structure (36). Strengthening the importance of the BCR-ABL1/JAK2 interplay, we showed that JAK2 activity was necessary for BCR-ABL1 kinaseindependent induction, nuclear localization, and transcriptional activity of $\beta$-catenin in CML HSCs. Indeed, retroviral BCR-ABL1 transduction/transplantation studies with $\beta$-catenin WT and null cells suggested the importance of $\beta$-catenin for survival/self-renewal of dividing BCR-ABL1 ${ }^{+}$stem/progenitors and revealed that $\mathrm{BCR}-$ ABL1 induces $\beta$-catenin in an imatinib-insensitive manner $(14,31)$. Moreover, loss of $\beta$-catenin in CML mice resulted in delayed disease recurrence/relapse upon imatinib discontinuation and reduced frequency of leukemic, but not normal, HSCs (37). The existence of a JAK2- $\beta$-catenin pathway requiring BCR-ABL1 expression, but not its activity, does not contradict the BCR-ABL1 kinase-dependent $\beta$-catenin induction/stabilization observed in CML progenitors $(38,39)$. Indeed, TKI sensitivity characterizes dividing, but not quiescent, CML cells. In this regard, we reported that induction of the JAK2-SET pathway and PP2A inhibition occurred in a BCR-ABL1 kinase-dependent manner in CD34+ $\mathrm{CML}$ progenitors and BCR$\mathrm{ABL}^{+}$lines $(15,16,27)$. We showed that SET-mediated PP2A inactivation was essential for survival/self-renewal of quiescent CML HSCs and maintenance of an active JAK2 $\beta$-catenin pathway and that PP2A is suppressed in CML HSCs in a BCR-ABL1 kinase-independent, JAK2-dependent manner. This is not surprising, as JAK2 and PP2A negatively regulated each other (Figure 4E) in hematopoietic progenitors $(15,16,27,40)$. Thus, we conclude that PP2A inactivation has a pivotal role in the maintenance of leukemic HSC survival/self-renewal in TKI-treated CML patients.

We provided evidence that the PP2A activator FTY720 is not toxic to normal HSCs, but markedly impairs self-renewal and survival of quiescent CML HSCs. Surprisingly, these effects were not due to BCR-ABL1 inactivation, as we previously reported in CML progenitors (16), but were mostly mediated by the PP2A-induced inactivation of JAK2 and $\beta$-catenin. This was not unexpected; in fact, FTY720-dependent restoration of PP2A activity in leukemic progenitors is accompanied by decreased $\mathrm{PP} 2 \mathrm{Ac}^{\mathrm{Y} 307}$ phosphorylation, a JAK2-dependent direct mechanism of PP2A inactivation (40). Likewise, PAD-induced (FTY720 and 1,9-dideoxy forskolin) $\beta$-catenin inhibition could depend not only on JAK2 inhibition, but also on a direct effect of PP2A on $\beta$-catenin itself and GSK-3 $\beta$, which is part of the $\beta$-catenin destruction complex $(29,41)$. The dependence of FTY720 antileukemic HSC activity on PP2A reactivation and consequent inhibition of $\beta$-catenin is also supported by the counteracting effect of the PP2A inhibitor okadaic acid (15) on FTY720 and the JAK2 inhibitor TG101348, as well as that of the GSK-3 $\beta$ inhibitors on FTY720. FTY720 has strong in vitro and in vivo proapoptotic activities toward leukemic stem/progenitor cells with a desirable nontoxic profile in ex vivo primary cells and longterm animal studies (16). FTY720-induced immunosuppression (20) leading to lymphopenia could be avoided by using FTY720 derivatives that are equally effective in killing leukemic HSCs and progenitors, but do not require phosphorylation, which is the main step for the immunosuppressive activity of FTY720 and is dispensable for the antileukemic activity of this compound (20).

In conclusion, our present findings provided evidence that an oncogenic tyrosine kinase like BCR-ABL1 can exert its leukemogenic potential in spite of its activity by controlling leukemic stem cell behavior through recruitment and activation of other oncogenes (e.g., JAK2), and that CML cure is potentially achievable by eradicating the disease at the stem cell level using PADs. Moreover, the present study and our previous reports $(15,16)$ strongly support also testing PADs in all types of $\mathrm{Ph}^{+}$leukemias. Importantly, the advantage of using PADs is in their potentially high therapeutic index, as they selectively activate PP2A in leukemic HSCs/progenitors without adverse effects on normal hematopoiesis. Notably, a rather short-term in vivo treatment with FTY720 did not lead to complete eradication of leukemia-initiating cells, as their reduction did not achieve a full log difference; however, the safety profile of PADs like FTY720 and its derivatives allows for prolonged treatment, which may entirely deplete the leukemic stem cell reservoir through sustained activity of PP2A against leukemic self-renewal and survival. Furthermore, because of their wider implications on other molecular networks (Figure 7) that control CML stem cell fate $(10,12,14$, $42)$ and are regulated by $\operatorname{PP} 2 A(29,41,43,44)$, the biological and clinical importance of our findings is not limited to CML, but may be extended to other stem cell malignancies.

\section{Methods}

\section{Cell lines}

The 32Dcl3 and $\mathrm{K} 562$ cell lines were maintained in culture in Iscove modified Dulbecco medium (IMDM), 10\% FBS, and $2 \mathrm{mM}$ L-glutamine. 32D-p210 ${ }^{\text {BCR-ABL1 }}, \mathrm{p} 210^{\mathrm{K} 1172 \mathrm{R}}$, and JAK2-expressing 32Dcl3 cells were generated by retroviral infection as previously described (45). 
A
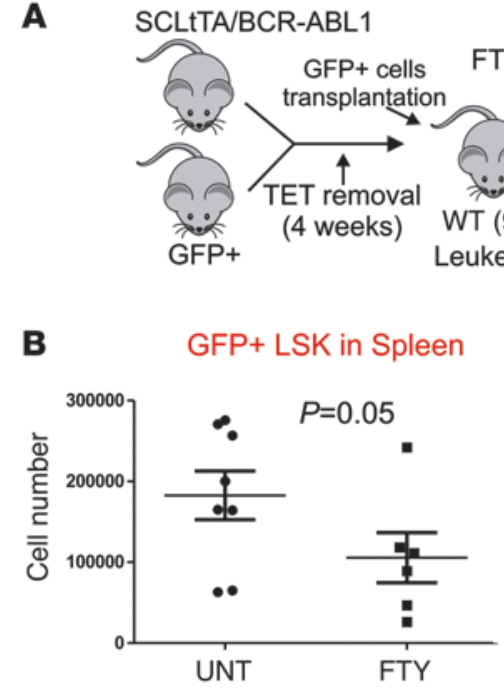

FTY720 treatment

4 weeks

\section{Transplant bone marrow secondary recipients (limiting dilutions)}

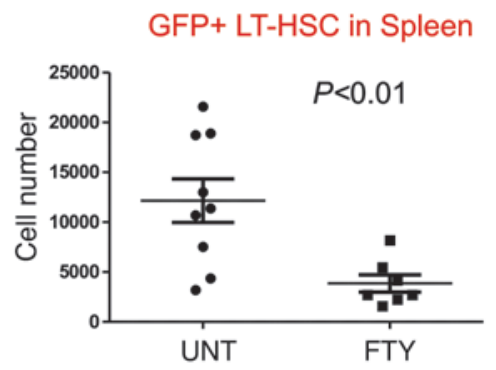

GFP+ LT-HSC in Bone Marrow

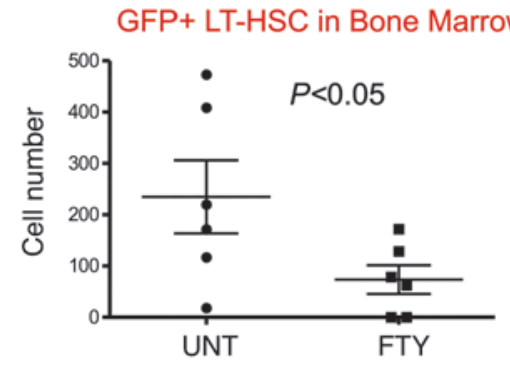

C
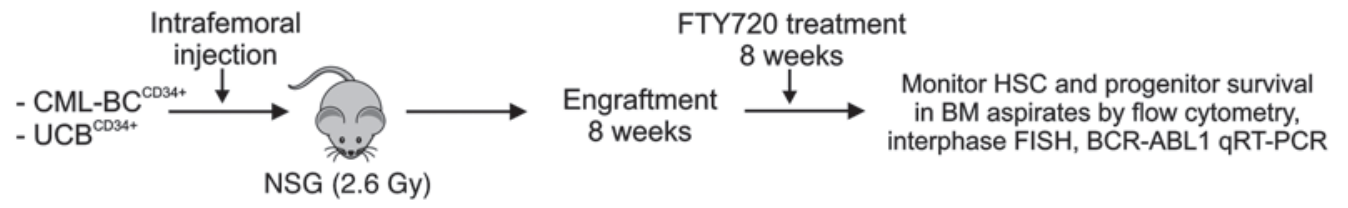

D
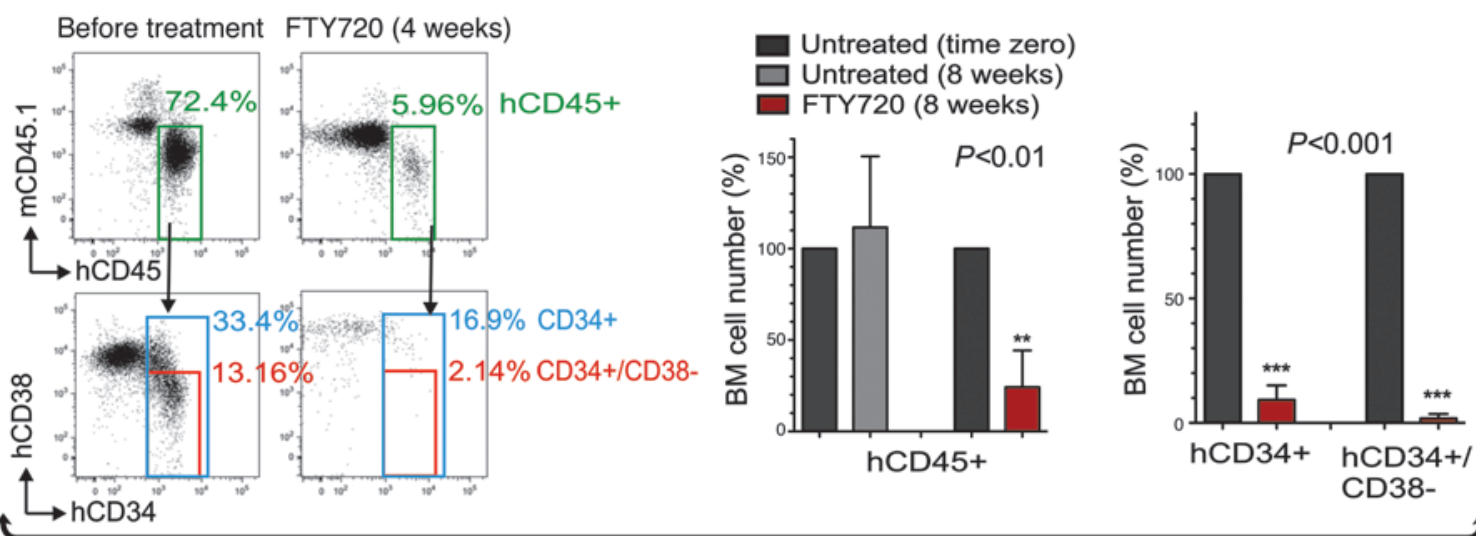

CML (BM aspirate)

E

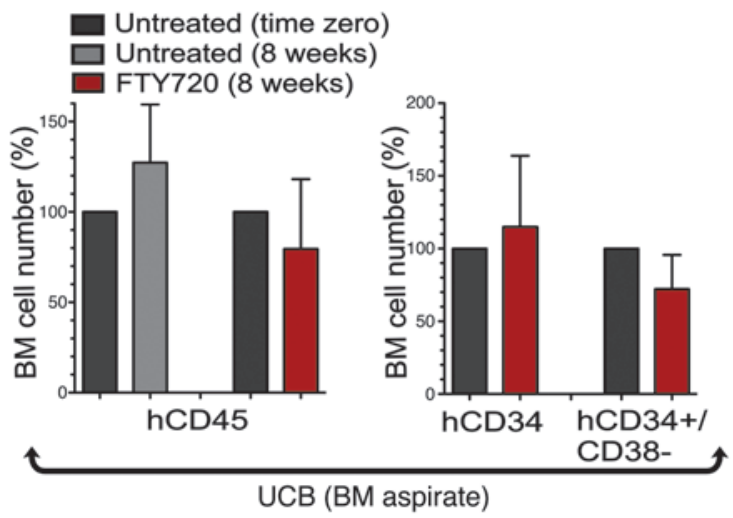

$\mathbf{F}$

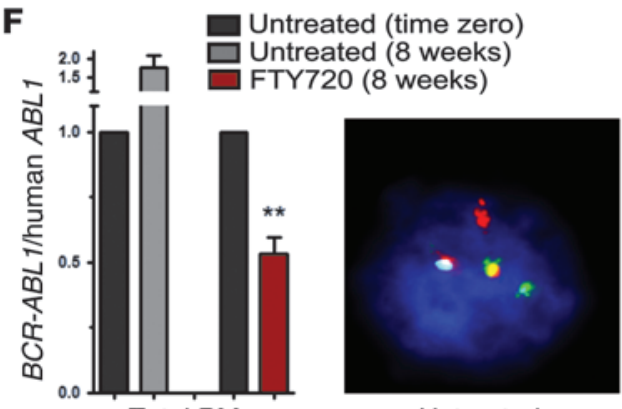

Untreated

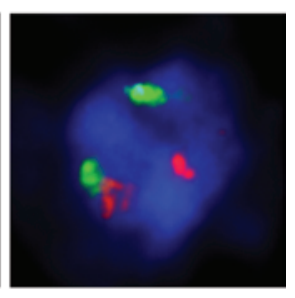

FTY720 (4 weeks) 


\section{Figure 6}

FTY720 suppresses mouse BCR-ABL1 + LT-HSC and human CML stem and progenitor cell survival in vivo. (A) Transplantation of BCR-ABL1/ $\mathrm{GFP}^{+}$cells derived from transgenic BCR-ABL1-tg/GFP mice into primary and secondary recipients. (B) Effect of FTY720 (4 weeks) on the absolute numbers of GFP+(leukemic) LSK cells and LT-HSCs in mice transplanted with leukemic BM cells. (C) Xenotransplantation of human CML-BC and UCB CD34+ cells into NSG mice. (D) Percent hCD45+ cells, hCD34+ progenitors, and hCD34+CD38- $\mathrm{HSC}$-enriched cell fraction in a representative CML xenotransplanted NSG mouse before and after 4 weeks of FTY720 treatment. Also shown are levels of hCD45+, hCD34+, and hCD34+CD38- cells in BM aspirated at time of engraftment (time 0 ) and after 8 weeks in untreated and FTY720-treated NSG mice (8-10 per group) intrafemorally transplanted with $C D 34^{+}$cells from CML-BC patients $(n=3)$. (E) Frequency of cells as in $\mathbf{D}$, but with CD34+ cells transplanted from UCB donors $(n=3)$. (F) qRT-PCR-mediated analysis of $B C R-A B L 1$ transcripts in $B M$ aspirates of CML-engrafted mice left untreated or treated with FTY720. Also shown is a representative cell of $B C R-A B L 1$ interphase FISH on FACS-sorted hCD45+ cells from BM aspirates of untreated and 4-week FTY720-treated mice. Original magnification, $\times 1,000 .{ }^{*} P<0.05,{ }^{\star \star} P<0.01,{ }^{\star \star \star} P<0.001$, Student's $t$ test.

\section{Primary cells}

Progenitors $\left(\mathrm{CD} 34^{+}\right)$and HSC-enriched fractions $\left(\mathrm{CD} 34^{+} \mathrm{CD} 38^{-}\right.$; $\mathrm{CD} 34^{+} \mathrm{CD} 38^{-} \mathrm{CD} 90^{+}$) were isolated from $\mathrm{UCB}$ and from mononuclear cells from $\mathrm{BM}$ or peripheral blood (PB) from 96 total patients with unidentifiable CML-CP $(n=34)$, accelerated phase CML $(n=6)$, or CML$\mathrm{BC}(n=56)$ as well as from 27 healthy donors (Supplemental Table 1). Frozen samples of $\mathrm{CD} 34^{+} \mathrm{NBM}$ cells from different healthy donors were obtained from Cincinnati Children's Hospital and The Ohio State University. All studies were performed with human CML specimens obtained from The Ohio State University Leukemia Tissue Bank; the Division of Hematology, Maisonneuve-Rosemont Hospital; the North Glasgow University Hospital Division, University of Glasgow; the Hammersmith Hospital, Imperial College London; and the Department of Hematology, Aarhus University Hospital. The percentage of CML-CP and CML-BC $\mathrm{Ph}^{+}$ cells analyzed by FISH ranged $75 \%-100 \%$. UCB units were collected by the Translational Trials Development Support Laboratory of Cincinnati Children's Hospital Research Foundation.

$\mathrm{BM}$ cells were obtained from the femurs and tibias of WT FVB/N mice and from previously described 8-week-induced leukemic SCLtTA/BCR-ABL1 mice (46). BM mononuclear cells were used for isolation of the $\mathrm{Lin}^{-}$fraction (lineage depletion kit; Miltenyi Biotech). When cultured, murine stem/ progenitor cells were kept in complete IMDM supplemented with murine IL-3 $(2 \mathrm{ng} / \mathrm{ml})$, IL-6 (1.2 ng/ml), KL (10 ng/ml), Flt-3 ligand $(5 \mathrm{ng} / \mathrm{ml})$, and GM-CSF $(5 \mathrm{ng} / \mathrm{ml})$.

Cells were treated as indicated with the following reagents: imatinib mesylate (Novartis); 1,9-dideoxy-forskolin, JAK inhibitor I (EMD Chemicals); TG101210, TG101348 (TargeGen Inc.); lithium chloride (Fisher); SB216763 (Cayman Chemicals). FTY720 was synthesized with subsequent HPLC purification (47), and identity/purity was confirmed by nuclear magnetic resonance and mass spectrometry. (S)-FTY720-OMe, OSU-2S, and (S)-FTY720-regioisomer were synthesized as described previously $(48,49)$.

\section{Flow cytometric analysis and sorting of HSCs}

Primary CD34 ${ }^{+}$cells were isolated by magnetic cell sorting (CD34 MultiSort; Miltenyi Biotec) and kept in IMDM supplemented with 30\% FBS, $2 \mathrm{mM}$ L-glutamine, rhIL-3 $(20 \mathrm{ng} / \mathrm{ml})$, rhIL-6 $(20 \mathrm{ng} / \mathrm{ml})$, rhFlt-3 ligand $(100 \mathrm{ng} / \mathrm{ml})$, and rhKL $(100 \mathrm{ng} / \mathrm{ml})$ (Stem Cell Technologies). The CD $34^{+}$ fraction derived from the $\mathrm{BM}$ of healthy donors and the $\mathrm{PB}$ or $\mathrm{BM}$ of CML patients was stained with anti-CD34 FITC or PE, and anti-CD38
PE-Cy7 (BD Biosciences). The Lin ${ }^{-}$fraction of murine mononuclear cells was stained with anti-Sca-1 PE-Cy7 (BD Biosciences) and anti-c-kit APCAlexa Fluor 750 (eBioscience). CD34+CD38- and LSK fractions were sorted by fluorescence-activated cell sorting with a FACS Aria II instrument (BD Biosciences). Where indicated, the CD34+ and TKI-resistant (50-53) $\mathrm{CFSE}^{+} \mathrm{CD} 34^{+}$fractions from normal or $\mathrm{CML}$ samples, and the $\mathrm{CD} 34^{+}$fraction from pHIV7-sp1 shBCR-ABL1-transduced CML samples, were stained with anti-CD34 PE and anti-CD38 PE-Cy7 (BD Biosciences), fixed and permeabilized with the BD Cytofix/Cytoperm Kit (BD Biosciences), and stained with either a specific primary antibody or an isotype-matched control and a secondary goat $\mathrm{F}\left(\mathrm{ab}^{\prime}\right)$ anti-rabbit conjugated to Alexa Fluor 647 (Invitrogen); intracellular flow data are reported as fold change of the isotype-subtracted median fluorescence intensity (MFI) of the Alexa Fluor 647 signal. Primary antibodies used were rabbit anti-phospho-c-Abl (pY245; Cell Signaling Technology), rabbit anti-phospho-JAK2 (pY1007/1008; Cell Signaling Technology), and rabbit anti-SET (I2PPA; Globozyme).

\section{CFSE-mediated tracking of cell division}

CFSE-stained cells (CellTrace CFSE Proliferation Kit; Invitrogen) were cultured in the presence of the indicated drugs (dosed at time 0 and at day 3), and the cells were harvested after 3 or 6 days in culture and stained with anti-CD34 PE, Annexin-V V450, and the viability stain 7-AAD (BD Bioscience) to determine the number of viable quiescent cells $\left(\mathrm{CFSE}^{\max } \mathrm{CD} 34^{+} 7-\mathrm{AAD}^{-}\right)$and the percentage of quiescent and apoptosiscommitted cells $\left(\mathrm{CFSE}^{\max } \mathrm{CD} 34^{+}\right.$Annexin $\left.\mathrm{V}^{+} 7-\mathrm{AAD}^{+}\right)$. Cells were sorted into dividing and quiescent populations for Western blot analysis. For assessment of mouse quiescent leukemic HSCs, Lin $^{-}$cells from 8-weekinduced SCLtTA/BCR-ABL1 mice (24) were CFSE stained and used as described above. Quiescent cells $\left(\mathrm{CFSE}^{\max } \mathrm{CD} 34^{+}\right.$) were reported as a fraction of the initial number of $\mathrm{CD} 34^{+}$cells.

\section{LTC-IC and CFC/replating assays}

$2 \times 10^{6}$ mononuclear CML cells were cultured with a $1: 1$ mixture of irradiated (80 Gy) IL-3/G-CSF-producing M2-10B4 and IL-3/KL-producing SI/ SI murine fibroblasts in MyeloCult H5100 (StemCell Technologies) supplemented with hydrocortisone. Drugs were present during the first week of culture. Medium was replaced after 7 days, followed by weekly half-medium changes. After 6 weeks, adherent and floating cells were harvested, and $5 \times 10^{4}$ cells were plated into MethoCult H4435. LTC-IC-derived colonies were scored after 14 days. For CFC/replating, individual 14-day colonies from $10^{3}-10^{5} \mathrm{CD} 34^{+} \mathrm{CD} 38^{-} \mathrm{CML}$ or $0.2 \times 10^{3}-10^{3}$ leukemic LSK cells plated in $0.9 \%$ H4435 or M3234 MethoCult, respectively, containing KL, G-CSF, GMCSF, IL-3, IL-6, and Epo were replated and scored 2 weeks later.

\section{Table 1}

Serial BM transplant experiments

$\begin{array}{lcc}\text { BM cell dose } & \text { Untreated } & \text { FTY720 } \\ \text { Experiment } 1 & & \\ 2,000,000 & 5 / 6 & 2 / 8 \\ \text { Experiment 2 } & & \\ 2,000,000 & 8 / 8 & 5 / 7 \\ 1,000,000 & 7 / 7 & 3 / 7 \\ 500,000 & 4 / 8 & 0 / 8\end{array}$

Values represent incidence of LT-HSC engraftment $\left(\geq 0.1 \%\right.$ GFP ${ }^{+}$cells in $\mathrm{PB})$ at 16 weeks in secondary recipients transplanted with the indicated number of BM cells from untreated or FTY720-treated (4 weeks) animals. 

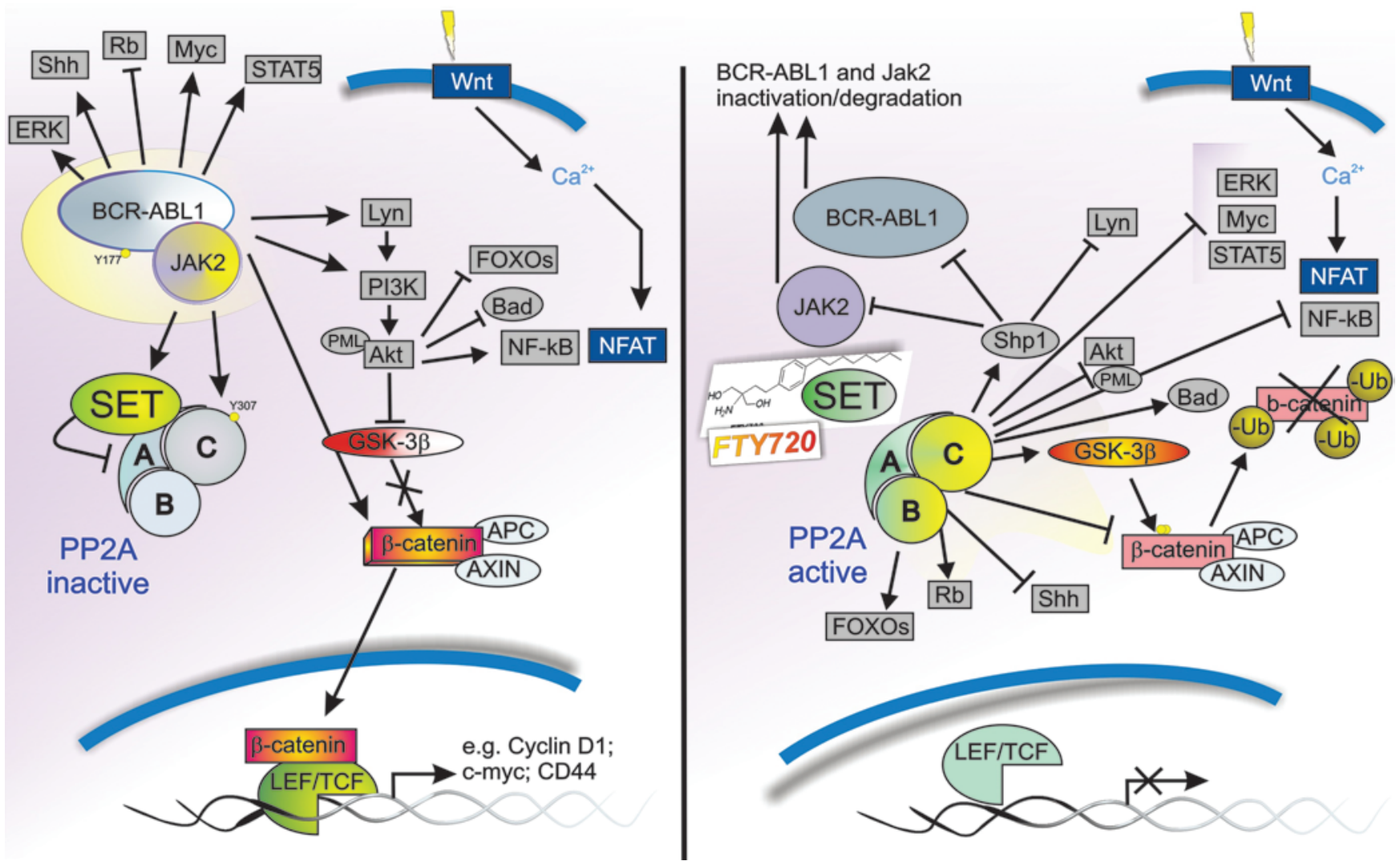

Figure 7

The PAD-sensitive network in CML HSCs. Shown is the BCR-ABL1/JAK2-SET/PP2A-GSK-3 $/ \beta$-catenin molecular network in untreated (left) and FTY720-treated (right) stem and progenitor CML cells.

\section{LEF/TCF reporter assay}

$\mathrm{CD} 34^{+} \mathrm{CD} 38^{-} \mathrm{CML}$ cells were transduced with $\mathrm{pBAR}$ or pfuBAR (negative control) $\beta$-catenin lentiviral reporter constructs (54), puromycin selected, and treated with the indicated drugs. Luciferase was measured using the Bright-Glo Luciferase system (Promega).

\section{Immunofluorescence and proximity ligation assay}

$\mathrm{CD} 34^{+} \mathrm{CD} 38^{-}$cells from CML patient samples or LSK cells derived from induced leukemic mice were sorted, treated in liquid culture with the indicated drugs, and cytospun onto glass slides. Slides were fixed in $3.7 \%$ formaldehyde; permeabilized with $0.05 \%$ Triton X-100; stained with an anti- $\beta$-catenin primary antibody (Cell Signaling), a secondary goat $\mathrm{F}\left(\mathrm{ab}^{\prime}\right)$ anti-rabbit conjugated to Alexa Fluor 647 , and the nuclear stain DAPI (Invitrogen); and mounted with Slowfade antifade reagent (Invitrogen). Microphotographs were obtained with a Zeiss LSM 510 confocal laser-scanning microscope with C-Apochromat 63/1.2 W objective. At least 3 fields per slide were acquired. For the proximity ligation assay, $\mathrm{CD} 34^{+} \mathrm{CD} 38^{-} \mathrm{CML}$ cells were treated, fixed, and permeabilized as described above. Slides were then simultaneously stained with a mix of mouse anti-PP2A (Millipore) and rabbit anti-SET (Globozyme) antibodies. The proximity ligation assay procedure (Duolink; Olink Bioscience) was performed according to the manufacturer's instructions. An average of $20 z$ stacks ( $10-\mu \mathrm{m}$ sections) were captured with a Zeiss LSM 510 confocal laser-scanning microscope with C-Apochromat $63 / 1.2 \mathrm{~W}$ objective; at least 3 fields per slide were acquired. 3 -dimensional projections were generated, and the number of positive signals per cell was calculated by ImageJ software (NIH).

\section{Lentiviral and retroviral transduction}

Lentiviral pseudotyped particles were produced by transient calcium phosphate transfection (ProFection mammalian transfection System; Promega) of 293T cells with the specific lentiviral vector $\left(18 \mu \mathrm{g} / 175 \mathrm{~cm}^{2}\right)$, the psPAX2 packaging construct (Addgene plasmid 12260, $9 \mu \mathrm{g} / 175 \mathrm{~cm}^{2}$; provided by D. Trono, Swiss Institute of Technology, Lausanne, Switzerland); and the G-glycoprotein of vesicular stomatitis virus (VSV-G, $1.8 \mu \mathrm{g} / 175 \mathrm{~cm}^{2}$ ). Viral supernatant was collected 24 and 48 hours after transfection, mixed 1:4 with a $40 \%$ PEG-8000 solution, incubated overnight at $4^{\circ} \mathrm{C}$, and concentrated to 1:100 of the original volume by centrifugation ( 30 minutes, $1,500 \mathrm{~g}$ at $4^{\circ} \mathrm{C}$ ). Viral titer was determined by transduction of $293 \mathrm{~T}$ cells with serial dilutions of concentrated vector, and the percentage of $\mathrm{GFP}^{+}$cells was determined 48 hours after transduction. Target cells $\left(0.5 \times 10^{6} \mathrm{cells} / \mathrm{ml}\right)$ were transduced by spinoculation $(1,200 \mathrm{~g}$ for 2 hours; ref. 55$)$ with viral supernatants diluted (MOI 10) in polybrene-containing $(4 \mathrm{mg} / \mathrm{ml})$ complete medium. GFP-mediated FACS sorting or puromycin selection was initiated 48 hours after infection. Retroviral ecotropic particles were produced by transient calcium phosphate transfection (ProFection mammalian transfection System; Promega) of Phoenix cells (56). Viral supernatant was collected 36 and 48 hours after transfection and concentrated to 1:50 original volume by overnight ultracentrifugation $\left(18,000 \mathrm{~g} ; 4^{\circ} \mathrm{C}\right)$. Viral titer was determined by transduction of $3 \mathrm{~T} 3$ cells with serial dilutions of concentrated vector, and the percentage of $\mathrm{GFP}^{+}$cells was determined after 48 hours. Retroviral infection of freshly isolated LSK cells was performed in non-tissue culture multiwell plates precoated with fibronectin $\mathrm{CH} 296$ fragment (Takara Bio Inc.) at $4 \mu \mathrm{g} / \mathrm{cm}^{2}$. Cells $\left(2 \times 10^{6}\right)$ were incubated overnight in the presence of viral particles, and the $\mathrm{GFP}^{+}$fraction was isolated 36 hours after transduction. 


\section{Plasmids}

pHIV7-GFP-sp1. The lentiviral pHIV7-GFP vector containing the shRNA specific for the b3a2 (e14a2) translocation breakpoint of BCR/ABL was provided by J. Rossi (Beckman Research Institute, City of Hope, Duarte, California, USA). Prior to transduction, the presence of the b3a2 BCRABL1 translocation was assessed by RT-PCR, as previously described (57).

$p B A R$ and $p f u B A R$. The $\beta$-catenin-responsive luciferase reporter lentiviral vector PBAR contains 12 TCF binding sites separated by 5 nucleotide linkers directly upstream of a minimal TK promoter that drives the expression of firefly luciferase. The pfuBAR reporter is characterized by the substitution of 2 nucleotides in each TCF element that makes it unresponsive to $\beta$-catenin.

$p S R \alpha-p 210$ and $p S R \alpha-p 210-K 1172 R$. The plasmid pSR $\alpha M S V t k n e o-p 210$ has been described previously (58). The p210 kinase-deficient (K1172R) mutant was obtained from C. Sawyers (UCLA, Los Angeles, California, USA). MigR1-p210 (gift of W.S. Pear, University of Pennsylvania, Philadelphia, Pennsylvania, USA) and MigR1-p210-K1172R BCR-ABL have been previously generated by subcloning the WT and mutated BCR-ABL1 cDNA into the MigR1 EcoR1 site.

pNALDINI-HA-PP2Ac. The HA-tagged PP2Ac cDNA was PCR amplified from PHM6-HA-PP2Ac (15) and subcloned into the pNALDINI.CMV. IRES.EGFP lentiviral vector.

pGIPZ-shJAK2. The construct carrying the shRNA targeting human JAK2 was from Open Biosystems (clone ID V2LHS_61653).

\section{Western blot analysis and immunoprecipitation}

Lysates obtained from cell lines were subjected to SDS-PAGE and Western blot as described previously (15). Primary CML cells sorted from the CFSE tracking experiment were lysed in Laemmli buffer $(10 \mu \mathrm{l} / 3,000$ cells), denatured, and subjected to SDS-PAGE and Western blot. For immunoprecipitation, cells were lysed in 20 mM HEPES (pH 7.0), 150 $\mathrm{mM} \mathrm{NaCl}$, and $0.1 \% \mathrm{NP}-40$ supplemented with protease and phosphatase inhibitors. Lysates were precleared for 1.5 hours at $4^{\circ} \mathrm{C}$, immunoprecipitated overnight at $4^{\circ} \mathrm{C}$ with protein $\mathrm{G}$-plus agarose beads (Calbiochem) coated with anti-SET or anti-Abl antibody, and subjected to SDS-PAGE and immunoblotting. The antibodies used were as follows: anti-Abl (Ab3), anti-actin (EMD); anti-phosphotyrosine (4G10), anti-PP2Ac (Millipore); anti-GRB2 (BD Biosciences); anti- $\beta$-catenin, anti-phospho- $\beta$-catenin (pS552), anti-JAK2 (Cell Signaling Technology); anti-phospho-JAK2 (pY1007/1008) (Epitomics); anti-SET (Globozyme).

\section{PP2A phosphatase assay}

PP2Ac assays from whole cell lysates were carried out as described previously (15) using the PP2Ac immunoprecipitation phosphatase assay kit (Millipore). Briefly, protein lysates $(50 \mu \mathrm{g})$ in $100 \mu \mathrm{l}$ of $20 \mathrm{mM}$ HEPES (pH 7.0), $100 \mathrm{mM} \mathrm{NaCl}, 5 \mu \mathrm{g}$ PP2Ac antibody (Millipore), and $25 \mu \mathrm{l}$ protein A-agarose were added to $400 \mu \mathrm{l}$ of $50 \mathrm{mM}$ Tris (pH 7.0), $100 \mathrm{mM}$ $\mathrm{CaCl}_{2}$, and immunoprecipitates were carried out at $4^{\circ} \mathrm{C}$ for 2 hours. Immunoprecipitates were used in the phosphatase reaction according to the manufacturer's protocol.

\section{Liquid chromatography/electrospray ionization/tandem mass spectrometry (LC/ESI/MS/MS)}

LC/ESI/MS/MS analysis of FTY720 and FTY-P were performed on a TSQ Quantum triple quadrupole mass spectrometer (Thermo Scientific) operating in a Multiple Reaction Monitoring (MRM) positive ionization mode, as described previously (59). Briefly, cells were exposed to FTY720 or FTY-P $(2.5 \mu \mathrm{M})$ for 10 minutes and snap frozen. Cell pellets, fortified with internal standards (17C-sphingosine and 17C-sphingosine$1 \mathrm{P})$, were extracted with ethyl acetate/isopropanol/water (60:30:10 v/v).
The lysates were dried, reconstituted in methanol, injected on the mass spectrometer, and gradient eluted from the Hypersil BDS C8 column (Thermo Scientific) with $1 \mathrm{mM}$ methanolic ammonium formate and 2 $\mathrm{mM}$ aqueous ammonium formate mobile phase system. Analysis was performed using Xcalibur software. Calibration curves were constructed by plotting peak area ratios of synthetic standards, representing each target analyte, to the corresponding internal standard. The target analyte peak area ratios from the samples were similarly normalized to their respective internal standard and compared with the calibration curves using a linear regression model.

\section{BM serial transplantation assays and in vivo effect of FTY720 on LT-HSCs from transgenic BCR-ABL1 mice}

$2 \times 10^{6} \mathrm{GFP}^{+} \mathrm{BM}$ cells or $3 \times 10^{3} \mathrm{GFP}^{+} \mathrm{BM}$-derived LSK cells from 4-week-induced leukemic SCLtTA/BCR-ABL1/GFP mice (13) were transplanted into lethally irradiated $\mathrm{FVB} / \mathrm{N}$ mice. After the onset of neutrophilia (4 weeks after transplant), mice were treated with FTY720 $\left(10 \mathrm{mg} / \mathrm{kg} / \mathrm{d}\right.$, i.p.) or vehicle for 4 weeks. The number of total $\mathrm{GFP}^{+}$ cells and $\mathrm{GFP}^{+}$LT-HSCs ( $\left.\mathrm{Lin}^{-} \mathrm{Sca}-1^{+} \mathrm{Kit}^{+} \mathrm{FLt} 3^{-} \mathrm{CD} 150^{+} \mathrm{CD} 48^{-}\right)$was measured with a LSRII flow cytometer. BM cells $\left(2 \times 10^{6}, 1 \times 10^{6}\right.$, and $\left.0.5 \times 10^{6}\right)$ from treated and untreated mice (8 per group) mixed with $2 \times 10^{5} \mathrm{FVB} / \mathrm{N}$ BM cells were transplanted into lethally irradiated secondary recipients. Engraftment $\left(>0.1 \% \mathrm{GFP}^{+}\right.$in $\left.\mathrm{PB}\right)$ was monitored every 4 weeks, and LT-HSC frequency (13) was determined 16 weeks after secondary transplant using Poisson statistics.

\section{Engraftment of human normal and CML cells in immunodeficient NSG mice, and effect of FTY720 on leukemic and normal HSCs/ bematopoietic progenitors}

$\mathrm{CD} 34^{+}$cells were isolated from BM of CML patients $(n=3)$ or from UCB specimens $(n=3)$. Note that CML samples were from patients in blastic transformation with $\geq 75 \% \mathrm{Ph}^{+}$blasts. Sublethally irradiated (2.6 Gy) 6 - to 8-week-old NOD.Cg-Prkds scid $I L 2 r g^{t m 1 W j l} /$ SzJ (NSG; Jackson Laboratory) mice were intrafemorally injected with $1-3 \times 10^{6} \mathrm{CML}$ or $10^{5} \mathrm{UCB} \mathrm{CD} 34^{+}$ cells/mouse. Engraftment was assessed 8 weeks after transplant by antihuman CD45 (BD Biosciences) and anti-mouse CD45.1 flow staining of intrafemoral $\mathrm{BM}$ aspirates and $\mathrm{PB}$ from tail vein, as described previously (60). CML- and UCB-engrafted NSG mice (8-10 per group) were treated for 8 weeks with either FTY720 (10 mg/kg/d, i.p.) or PBS. Disease evolution and effect of FTY720 on the HSC-enriched $\left(\mathrm{CD} 45^{+} \mathrm{CD} 34^{+} \mathrm{CD} 38^{-}\right)$, primitive progenitor $\left(\mathrm{CD} 45^{+} \mathrm{CD} 34^{+}\right)$, myeloid cell $\left(\mathrm{CD} 45^{+} \mathrm{CD} 34^{+} \mathrm{CD} 33^{+}\right)$, B cell $\left(\mathrm{CD} 45^{+} \mathrm{CD} 19^{+}\right)$, and $\mathrm{T}$ cell $\left(\mathrm{CD} 45^{+} \mathrm{CD}^{+}\right)$compartments were determined before and after 4 or 8 weeks of FTY720 treatment by FACS-mediated analysis of $\mathrm{BM}$ aspirates and/or PB cells. $B C R-A B L 1$ transcript levels were monitored by qRT-PCR-mediated (Ipsogen) analysis of BCR-ABL1/ABL1 ratios in total RNA samples derived from BM aspirates of CML-engrafted animals at time of engraftment (time 0 ) and after 8 weeks of FTY720 treatment. Adverse effects or changes in animal behavior were not noted in FTY720-treated animals.

\section{FISH}

Human $\mathrm{CD}_{4} 5^{+}$cells from intrafemoral BM aspirates of untreated and 8-week FTY720-treated NSG mice engrafted with CD34+ CML-BC and UCB cells were FACS-isolated, dropped onto microscope slides, and fixed in a 3:1 methanol/acetic acid solution. A triple-color, dual-fusion BCR$A B L 1$ FISH probe was applied according to the manufacturer's instructions (Kreatech Diagnostics). Hybridized slides were counterstained with DAPI and visualized under an Olympus BX41 microscope. Images were captured using a Hammamatsu Orca II CCD camera and SmartCapture X software (Digital Scientific). 


\section{Statistics}

1-tailed Student's $t$ tests were performed using GraphPad Prism version 5.0a. A $P$ value less than 0.05 was considered significant.

\section{Study approval}

Patient samples were banked, not collected for this study, which was carried out with a waiver of informed consent and approval from The Ohio State University IRB. UCB units were collected by the Translational Trials Development Support Laboratory of Cincinnati Children's Hospital Research Foundation according to an IRB-approved protocol. Animal studies were performed according to IRB- and IACUC-approved protocols.

\section{Acknowledgments}

We thank B. Perazzona, R. Van Etten, X. Jiang, and J. Van Brocklyn for providing reagents; C.J. Eaves, J. Cancelas, and T.S. Ong for scientific discussion; J. Perrin for helping procure CML specimens; and S. Lee for editorial assistance. This work is dedicated to Carolyn Kraemer and her family, Bob Mills, and Tom Archdeacon for supporting this work through the Leukemia and Lymphoma Society. This work was supported by NIH grants CA095512 (to D. Perrotti), CA16058 (to The Ohio State Univer- sity Comprehensive Cancer Center), CA140158 (to J.C. Byrd), CA88932 (to B. Ogretmen), CA95684 (to R. Bhatia), CA49639 (to R.B. Arlinghaus), HL-083187 (to R. Bittman), and USPHS MO1 RR08084 (to Cincinnati Children's Hospital); by US Army CML Research Program grant W81XWH-07-1-0270 (to D. Perrotti); by the Leukemia and Lymphoma Society Scholarship (to D. Perrotti and J.C. Mulloy) and grant SCOR 7004-11 (to J.C. Byrd); by the American-Italian Cancer Foundation (to P. Neviani); by Fonds de la Recherche en Sante du Quebec (to D.-C. Roy); by the Danish Medical Research Council and the Danish Cancer Society and the Karen Elise Jensen Foundation (to P. Hokland); by Alex's Lemonade Stand (to J.C. Mulloy); and by Cancer Research UK grant C11074/A11008 (to T.L. Holyoake).

Received for publication January 23, 2013, and accepted in revised form July 3, 2013.

Address correspondence to: Danilo Perrotti, The Ohio State University Comprehensive Cancer Center, 892 Biomedical Research Tower, 460 West 12th Avenue, Columbus, Ohio 43210-2207, USA. Phone: 614.292.3255; Fax: 614.688.4181; E-mail: danilo.perrotti@osumc.edu.
1. Perrotti D, Jamieson C, Goldman J, Skorski T. Chronic myeloid leukemia: mechanisms of blastic transformation. JClin Invest. 2010;120(7):2254-2264.

2. Hughes TP, Branford S. Monitoring disease response to tyrosine kinase inhibitor therapy in CML. Hematology Am Soc Hematol Educ. 2009; 2009:477-487.

3. Rousselot $P$, et al. Imatinib mesylate discontinuation in patients with chronic myelogenous leukemia in complete molecular remission for more than 2 years. Blood. 2007;109(1):58-60.

4. Sobrinho-Simoes M, Wilczek V, Score J, Cross NC, Apperley JF, Melo JV. In search of the original leukemic clone in chronic myeloid leukemia patients in complete molecular remission after stem cell transplantation or imatinib. Blood. 2010; 116(8):1329-1335.

5. Pellicano F, Sinclair A, Holyoake TL. In search of CML stem cells' deadly weakness. Curr Hematol Malig Rep. 2011;6(2):82-87.

6. Chu S, et al. Detection of BCR-ABL kinase mutations in CD34+ cells from chronic myelogenous leukemia patients in complete cytogenetic remission on imatinib mesylate treatment. Blood. 2005; 105(5):2093-2098.

7. Corbin AS, Agarwal A, Loriaux M, Cortes J, Deininger MW, Druker BJ. Human chronic myeloid leukemia stem cells are insensitive to imatinib despite inhibition of BCR-ABL activity. J Clin Invest. 2011;121(1):396-409.

8. Hamilton A, et al. Chronic myeloid leukemia stem cells are not dependent on Bcr-Abl kinase activity for their survival. Blood. 2012;119(6):1501-1510.

9. Bellodi C, et al. Targeting autophagy potentiates tyrosine kinase inhibitor-induced cell death in Philadelphia chromosome-positive cells, including primary CML stem cells. J Clin Invest. 2009; 119(5):1109-1123.

10. Dierks C, et al. Expansion of Bcr-Abl-positive leukemic stem cells is dependent on Hedgehog pathway activation. Cancer Cell. 2008;14(3):238-249.

11. Heaney NB, et al. Bortezomib induces apoptosis in primitive chronic myeloid leukemia cells including LTC-IC and NOD/SCID repopulating cells. Blood. 2010;115(11):2241-2250.

12. Ito $\mathrm{K}$, et al. PML targeting eradicates quiescent leukaemia-initiating cells. Nature. 2008; 453(7198):1072-1078.

13. Zhang B, et al. Effective targeting of quiescent chronic myelogenous leukemia stem cells by histone deacetylase inhibitors in combination with imatinib mesylate. Cancer Cell. 2010;17(5):427-442.

14. Zhao C, et al. Loss of beta-catenin impairs the renewal of normal and CML stem cells in vivo. Cancer Cell. 2007;12(6):528-541.

15. Neviani $\mathrm{P}$, et al. The tumor suppressor PP2A is functionally inactivated in blast crisis CML through the inhibitory activity of the BCR/ABL-regulated SET protein. Cancer Cell. 2005;8(5):355-368.

16. Neviani $P$, et al. FTY720, a new alternative for treating blast crisis chronic myelogenous leukemia and Philadelphia chromosome-positive acute lymphocytic leukemia. J Clin Invest. 2007;117(9):2408-2421.

17. Roberts KG, et al. Essential requirement for PP2A inhibition by the oncogenic receptor c-KIT suggests $\mathrm{PP} 2 \mathrm{~A}$ reactivation as a strategy to treat $\mathrm{c}-\mathrm{KIT}+$ cancers. Cancer Res. 2010;70(13):5438-5447.

18. Nagaoka Y, Otsuki K, Fujita T, Uesato S. Effects of phosphorylation of immunomodulatory agent FTY720 (fingolimod) on antiproliferative activity against breast and colon cancer cells. Biol Pharm Bull. 2008;31(6):1177-1181.

19. Perrotti D, Neviani P. PP2A: a target for anticancer therapy. Lancet Oncol. 2013;14(6):e229-e238.

20. Aktas O, Kury P, Kieseier B, Hartung HP. Fingolimod is a potential novel therapy for multiple sclerosis. Nat Rev Neurol. 2010;6(7):373-382.

21. Brinkmann V. FTY720 (fingolimod) in Multiple Sclerosis: therapeutic effects in the immune and the central nervous system. Br J Pharmacol. 2009;158(5):1173-1182.

22. Bhatia M, Wang JC, Kapp U, Bonnet D, Dick JE. Purification of primitive human hematopoietic cells capable of repopulating immune-deficient mice. Proc Natl Acad Sci U S A. 1997;94(10):5320-5325.

23. Holyoake T, Jiang X, Eaves C, Eaves A. Isolation of a highly quiescent subpopulation of primitive leukemic cells in chronic myeloid leukemia. Blood. 1999;94(6):2056-2064.

24 . Schemionek M, et al. BCR-ABL enhances differentiation of long-term repopulating hematopoietic stem cells. Blood. 2010;115(16):3185-3195.

25. Kimura T, et al. The sphingosine 1-phosphate receptor agonist FTY720 supports CXCR4dependent migration and bone marrow homing of human CD34+ progenitor cells. Blood. 2004; 103(12):4478-4486

26. Zemann B, et al. Sphingosine kinase type 2 is essential for lymphopenia induced by the immunomodulatory drug FTY720. Blood. 2006;107(4):1454-1458.
27. Samanta AK, et al. Jak2 inhibition deactivates Lyn kinase through the SET-PP2A-SHP1 pathway, causing apoptosis in drug-resistant cells from chronic myelogenous leukemia patients. Oncogene. 2009;28(14):1669-1681.

28. Samanta A, et al. Janus kinase 2 regulates Bcr-Abl signaling in chronic myeloid leukemia. Leukemia. 2011;25(3):463-472.

29. Seeling JM, Miller JR, Gil R, Moon RT, White R, Virshup DM. Regulation of beta-catenin signaling by the B56 subunit of protein phosphatase 2A. Science. 1999;283(5410):2089-2091.

30. Fleming HE, et al. Wnt signaling in the niche enforces hematopoietic stem cell quiescence and is necessary to preserve self-renewal in vivo. Cell Stem Cell. 2008;2(3):274-283.

31. Hu Y, Chen Y, Douglas L, Li S. $\beta$-Catenin is essential for survival of leukemic stem cells insensitive to kinase inhibition in mice with BCR-ABLinduced chronic myeloid leukemia. Lenkemia. 2009;23(1):109-116.

32. Reya $\mathrm{T}$, et al. A role for Wnt signalling in selfrenewal of haematopoietic stem cells. Nature. 2003;423(6938):409-414.

33. Bumm T, et al. Clonal chromosomal abnormalities in CD34+/CD38- hematopoietic cells from cytogenetically normal chronic myeloid leukemia patients with a complete cytogenetic response to tyrosine kinase inhibitors. Leukemia. 2010;24(8):1525-1528.

34. Jiang $X$, et al. Chronic myeloid leukemia stem cells possess multiple unique features of resistance to BCR-ABL targeted therapies. Lenkemia. 2007;21(5):926-935.

35. Sengupta A, Arnett J, Dunn S, Williams DA, Cancelas JA. Rac2 GTPase deficiency depletes BCR$\mathrm{ABL}+$ leukemic stem cells and progenitors in vivo. Blood. 2010;116(1):81-84.

36. Samanta AK, Chakraborty SN, Wang Y, Schlette E, Reddy EP, Arlinghaus RB. Destabilization of Bcr-Abl/Jak2 network by a Jak2/Abl kinase inhibitor ON044580 overcomes drug resistance in blast crisis chronic myelogenous leukemia (CML). Genes Cancer. 2010;1(4):346-359.

37. Heidel FH, et al. Genetic and pharmacologic inhibition of beta-catenin targets imatinib-resistant leukemia stem cells in CML. Cell Stem Cell. 2012;10(4):412-424.

38. Coluccia AM, et al. Bcr-Abl stabilizes beta-catenin in chronic myeloid leukemia through its tyrosine phosphorylation. EMBO J. 2007;26(5):1456-1466. 
39. Jamieson CH, et al. Granulocyte-macrophage progenitors as candidate leukemic stem cells in blastcrisis CML. N Engl J Med. 2004;351(7):657-667.

40. Yokoyama N, Reich NC, Miller WT. Involvement of protein phosphatase $2 \mathrm{~A}$ in the interleukin-3-stimulated Jak2-Stat5 signaling pathway. J Interferon Cytokine Res. 2001;21(6):369-378.

41. Patturajan M, et al. DeltaNp63 induces betacatenin nuclear accumulation and signaling. Cancer Cell. 2002;1(4):369-379.

42. Gregory MA, et al. Wnt/Ca2+/NFAT signaling maintains survival of $\mathrm{Ph}+$ leukemia cells upon inhibition of Bcr-Abl. Cancer Cell. 2010;18(1):74-87.

43. Trotman LC, Alimonti A, Scaglioni PP, Koutcher JA, Cordon-Cardo C, Pandolfi PP. Identification of a tumour suppressor network opposing nuclear Akt function. Nature. 2006;441(7092):523-527.

44. Krauss S, Foerster J, Schneider R, Schweiger S. Protein phosphatase $2 \mathrm{~A}$ and rapamycin regulate the nuclear localization and activity of the transcription factor GLI3. Cancer Res. 2008;68(12):4658-4665.

45. Perrotti D, et al. BCR-ABL suppresses C/EBPalpha expression through inhibitory action of hnRNP E2. Nat Genet. 2002;30(1):48-58.

46. Koschmieder S, et al. Inducible chronic phase of myeloid leukemia with expansion of hematopoietic stem cells in a transgenic model of BCR-ABL leukemogenesis. Blood. 2005;105(1):324-334.

47. Seidel G, Laurich D, Furstner A. Iron-catalyzed cross-coupling reactions. A scalable synthesis of the immunosuppressive agent FTY720. J Org Chem. 2004;69(11):3950-3952.

48. Lim KG, Sun C, Bittman R, Pyne NJ, Pyne S. (R)FTY720 methyl ether is a specific sphingosine kinase 2 inhibitor: Effect on sphingosine kinase 2 expression in HEK 293 cells and actin rearrangement and survival of MCF-7 breast cancer cells. Cell Signal. 2011;23(10):1590-1595.

49. Omar HA, et al. Antitumor effects of OSU$2 \mathrm{~S}$, a nonimmunosuppressive analogue of FTY720, in hepatocellular carcinoma. Hepatology. 2011;53(6):1943-1958

50. Copland M, et al. Dasatinib (BMS-354825) targets an earlier progenitor population than imatinib in primary CML but does not eliminate the quiescent fraction. Blood. 2006;107(11):4532-4539.

51. Graham SM, et al. Primitive, quiescent, Philadelphia-positive stem cells from patients with chronic myeloid leukemia are insensitive to STI571 in vitro. Blood. 2002;99(1):319-325.

52. Holtz MS, Forman SJ, Bhatia R. Nonproliferating CML CD34+ progenitors are resistant to apoptosis induced by a wide range of proapoptotic stimuli. Lenkemia. 2005;19(6):1034-1041.

53. Jorgensen HG, Allan EK, Jordanides NE, Mountford JC, Holyoake TL. Nilotinib exerts equipotent antiproliferative effects to imatinib and does not induce apoptosis in CD34+ CML cells. Blood.
2007;109(9):4016-4019

54. Major MB, et al. Wilms tumor suppressor WTX negatively regulates WNT/beta-catenin signaling. Science. 2007;316(5827):1043-1046.

55. O'Doherty U, Swiggard WJ, Malim MH. Human immunodeficiency virus type 1 spinoculation enhances infection through virus binding. J Virol. 2000;74(21):10074-10080.

56. Dorrance AM, et al. The Rac GTPase effector p21-activated kinase is essential for hematopoietic stem/progenitor cell migration and engraftment. Blood. 2013;121(13):2474-2482.

57. Sidorova J, Saltykova LB, Lyschov AA, Zaritskey A, Abdulkadyrov KM, Blinov MN. A rapid RT-PCR based method for the detection of BCR-ABL translocation. Mol Pathol. 1997;50(5):266-268.

58. Skorski T, et al. Transformation of hematopoietic cells by $B C R / A B L$ requires activation of a PI-3k/Akt-dependent pathway. EMBO J. 1997;16(20):6151-6161.

59. Bielawski J, Szulc ZM, Hannun YA, Bielawska A. Simultaneous quantitative analysis of bioactive sphingolipids by high-performance liquid chromatography-tandem mass spectrometry. Methods. 2006;39(2):82-91.

60. Wunderlich M, et al. AML xenograft efficiency is significantly improved in NOD/SCID-IL2RG mice constitutively expressing human SCF, GM-CSF and IL-3. Lenkemia. 2010;24(10):1785-1788. 